\title{
A Hydrogel-Based Tumor Model for the Evaluation of Nanoparticle-Based Cancer Therapeutics
}

\author{
${\text { Xian Xua }{ }^{\mathrm{a}} \text {, Chandran R. Sabanayagam }}^{\mathrm{b}}$, Daniel A. Harrington ${ }^{\mathrm{c}}$, Mary C. Farach-Carson ${ }^{\mathrm{c}, \mathrm{d}}$, \\ and Xinqiao Jia ${ }^{a, d, e, *}$ \\ aDepartment of Materials Science and Engineering, University of Delaware, Newark, DE 19716, \\ USA \\ bDelaware Biotechnology Institute, University of Delaware, Newark, DE 19711, USA \\ 'Department of Biochemistry and Cell Biology, Rice University, Houston, TX 77251, USA \\ ${ }^{d}$ Center for Translational Cancer Research, University of Delaware, Newark, DE 19716, USA \\ eBiomedical Engineering Program, University of Delaware, Newark, DE 19716, USA
}

\begin{abstract}
Three-dimensional (3D) tissue-engineered tumor models have the potential to bridge the gap between monolayer cultures and patient-derived xenografts for the testing of nanoparticle (NP)based cancer therapeutics. In this study, a hydrogel-derived prostate cancer (PCa) model was developed for the in vitro evaluation of doxorubicin (Dox)-loaded polymer NPs (Dox-NPs). The hydrogels were synthesized using chemically modified hyaluronic acid (HA) carrying acrylate groups (HA-AC) or reactive thiols (HA-SH). The crosslinked hydrogel networks exhibited an estimated pore size of 70-100 nm, similar to the spacing of the extracellular matrices (ECM) surrounding tumor tissues. LNCaP PCa cells entrapped in the HA matrices formed distinct tumorlike multicellular aggregates with an average diameter of $50 \mu \mathrm{m}$ after 7 days of culture. Compared to cells grown on two-dimensional (2D) tissue culture plates, cells from the engineered tumoroids expressed significantly higher levels of multidrug resistance (MDR) proteins, including multidrug resistance protein 1 (MRP1) and lung resistance-related protein (LRP), both at the mRNA and the protein levels. Separately, Dox-NPs with an average diameter of $54 \pm 1 \mathrm{~nm}$ were prepared from amphiphilic block copolymers based on poly(ethylene glycol) (PEG) and poly( $\varepsilon$-caprolactone) (PCL) bearing pendant cyclic ketals. Dox-NPs were able to diffuse through the hydrogel matrices, penetrate into the tumoroid and be internalized by $\mathrm{LNCaP} \mathrm{PCa}$ cells through caveolae-mediated endocytosis and macropinocytosis pathways. Compared to 2D cultures, LNCaP PCa cells cultured as multicellular aggregates in HA hydrogel were more resistant to Dox and Dox-NPs treatments. Moreover, the NP-based Dox formulation could bypass the drug efflux function of MRP1, thereby partially reversing the resistance to free Dox in 3D cultures. Overall, the engineered tumor model has the potential to provide predictable results on the efficacy of NP-based cancer therapeutics.
\end{abstract}

\footnotetext{
(C) 2013 Elsevier Ltd. All rights reserved.

*To whom correspondence should be addressed: Xinqiao Jia, 201 DuPont Hall, Department of Materials Science and Engineering, University of Delaware, Newark, DE, 19716, USA. Phone: 302-831-6553, Fax: 302-831-4545, xjia@udel.edu..

Publisher's Disclaimer: This is a PDF file of an unedited manuscript that has been accepted for publication. As a service to our customers we are providing this early version of the manuscript. The manuscript will undergo copyediting, typesetting, and review of the resulting proof before it is published in its final citable form. Please note that during the production process errors may be discovered which could affect the content, and all legal disclaimers that apply to the journal pertain.
} 


\section{Keywords}

Hyaluronic acid; hydrogel; 3D tumor model; nanoparticles; cancer therapeutics; drug resistance

\section{Introduction}

Over the past few decades, a concerted effort has been made to develop nanotechnologybased cancer diagnosis and therapy, with the premise of potentially prolonging patients' life expectancy, at the same time reducing treatment-related side effects [1,2]. Encapsulating anticancer drugs in polymeric nanoparticles (NPs) are proposed, and in some cases have been shown, to improve the pharmacological properties of drugs [3]. The NP-based drug delivery systems also have the potential to increase the therapeutic efficacy through the enhanced permeability and retention (EPR) effect or the active targeting strategies [4]. To date, the promise of nanomedicine in patients has not been fully realized owing to the numerous biological barriers to the delivery of cancer therapeutics $[5,6]$.

Currently, preliminary screening of NP-based cancer therapeutics is usually performed on two-dimensional (2D), monolayer cell culture systems. While straightforward and easy to perform, 2D cultures identify promising drug formulations that do not translate similarly in vivo in animal models or in patients [7], and many limitations associated with NP formulations are not discovered until a later stage of product development. The inconsistency in therapeutic outcomes can be attributed, in part, to the inability of monolayer cultures to accurately account for the extracellular barriers [8]. While NPs delivered to a monolayer cell culture typically reach cells without any physical restriction, the diffusion of NPs administrated in vivo would be hindered by the complex, tumor-associated extracellular matrix $(\mathrm{ECM})[8,9]$. The $3 \mathrm{D}$ organization of a tumor mess also fundamentally alters the diffusion profile for drugs, both through the cell-cell contacts and cell-matrix interactions [8].

In addition to altered cell organizations and extracellular environments, 2D monolayer cultures promote cells to adopt a non-natural phenotype, thereby influencing cellular responses to the delivered drugs [8]. Whereas cells in 2D cultures are exposed to a uniform environment with sufficient oxygen and nutrients, cells in the solid tumor tissues are exposed to gradients of critical chemical and biological signals [10]. Such a unique microenvironment can exert both stimulatory and inhibitory effects on tumor progression [10]. Moreover, tumor cells from cancer patients are frequently found to be resistant to a broad spectrum of chemotherapeutic drugs without previous exposure to those cytotoxic agents [11-13]. The intrinsic drug resistance can be attributed, in part to the overexpression of the multidrug resistance (MDR) proteins by tumor cells [12-14]. The tumor microenvironments, namely hypoxic conditions [12, 15], low nutrients supply [12] and low $\mathrm{pH}$ [16], all have been suggested to upregulate the expression of MDR proteins through specific cellular signaling pathways. Obviously, these essential environmental conditions cannot be recapitulated in traditional 2D monolayer cultures.

To overcome the limitations associated with traditional 2D monolayer cultures, various 3D culture systems aiming to recreate the tightly controlled molecular and mechanical microenvironment typical of tumors in vivo have been developed and characterized [17]. These systems may bridge the gap between 2D experiments and animal studies, providing physiologically relevant platforms for optimizing the drug formulations prior to the in vivo assessment [8]. Both natural (e.g. type I collagen [18-20] and basement membrane extract $[21,22])$ and synthetic materials (e.g. poly(e-caprolactone) (PCL) [23], poly(lactic-coglycolic acid) (PLGA) [24] and poly(ethylene glycol) (PEG) [25]) have been used as the 
scaffolding materials for the engineering of 3D tumor models. While natural materials derived from animal tissues are chemically ill-defined and suffer from batch-to-batch variations, most synthetic polymers are mechanically inappropriate and physiologically irrelevant [17]. These drawbacks limit their utility as artificial matrices for the construction of physiologically relevant tumor models.

We are interested in the in vitro engineering of 3D models of prostate cancer $(\mathrm{PCa})$ using hyaluronic acid (HA)-based hydrogel systems [17, 26, 27]. Produced by PCa cells and the stromal cells, HA is found to be enriched in the tumor-associated stroma [28, 29]. In addition to providing the structural support to the tumor tissues [17], HA interacts with its cell surface receptors, such as CD44 or RHAMM [26], to alter cell adhesion, migration and proliferation [26]. HA's biodegradation by hyaluronidase (HAase) helps the cancer cells to escape from the primary tumor mass [26], and degraded HA fragments promote angiogenesis to allow further tumor expansion [30]. Finally, HA protects the tumor tissues to evade the immune surveillance [28]. Using HA derivatives carrying orthogonal functionalities, we have developed HA-based hydrogel systems that not only support the tumoroid formation from PCa cells [27], but also simulate the reciprocal interactions with the tumor-associated stroma [17]. The resultant tumoroids closely mimic the morphology of the native tumor tissues and exhibit strong angiogenic potentials [17]. The engineered tumor models have also been used successfully to test the efficacy of anti-cancer drugs [27].

Herein, we report the physical and biological characterization of the hydrogel-based PCa model, and explore the utility of the engineered model in the evaluation of an anti-cancer drug, doxorubicin (Dox), both in its free form and encapsulated in polymeric NPs. To this end, HA-based hydrogels were prepared using HA derivatives carrying complementary reactive groups via a Michael-type addition reaction. The resultant hydrogel matrices were used for the 3D culture of LNCaP PCa cells in vitro. Separately, Dox was formulated into NPs derived from an amphiphilic block copolymer. The goal of this investigation was to repurpose the nanoformulations readily available in our laboratories rather than to design polymeric nanocarriers. Using the engineered tumor model, the transport properties of the NPs and the apoptotic properties of the nanoformulation were evaluated.

\section{Materials and methods}

\subsection{Chemicals and reagents}

HA (500 kDa, sodium salt) was generously donated by Genzyme Corporation (Cambridge, MA). All chemicals necessary for the synthesis of HA derivatives and the amphiphilic block copolymers were purchased from Sigma-Aldrich (St. Louis, MO). Doxorubicin hydrochloride (Dox-HCl) was obtained from BIOTANG Inc. (Waltham, MA). Nile red (NR), bovine testicular HAase (30,000 U/mg), bovine serum albumin (BSA), sucrose, chlorpromazine hydrochloride, methyl- $\beta$-cyclodextrin (M- $\beta-C D)$, genistein, colchicine and quercetin were purchased from Sigma-Aldrich (St. Louis, MO). Cell Titer-Blue ${ }^{\circledR}$ cell viability assay was obtained from Promega (Madison, WI). PEGylated (methoxy-PEG5000$\mathrm{SH}$ ) gold nanoparticles (PEG-AuNPs) were purchased from Cytodiagnostics (Burlington, ON). Cell Death Detection ELISA ${ }^{\text {PLUS }}$ was obtained from Roche Applied Science (Mannheim, Germany). Mouse anti-multidrug resistance protein 1 (MRP1) mAb (MRPm6) was purchased from Kamiya Biomedical Company (Seattle, WA). Mouse anti-lung resistance-related protein (LRP) mAb (LRP 1014) and goat anti-mouse IgG-FITC were obtained from Santa Cruz Biotechnology (Dallas, TX). All cell culture reagents were purchased from Life Technologies (Grand Island, NY). All other reagents were used as received unless otherwise noted. 


\subsection{Particle preparation and drug/dye encapsulation}

Amphiphilic block copolymers consisting of hydrophilic PEG and hydrophobic polyester bearing pendent cyclic ketals [PEG- $b$-P(CL-ran-TSU)] were synthesized by ring-opening co-polymerization of $\varepsilon$-caprolactone (CL) and 1,4,8-trioxaspiro-(4,6)-9-undecanone (TSU), using a-hydroxyl, $\omega$-methoxy PEG as the initiator and stannous octoate as the catalyst [31]. At a $20 \mathrm{wt} \%$ TSU in feed, the copolymer (abbreviated as ECT2) was found to contain 14 mol\% TSU in the hydrophobic segment. ECT2 with a number average molecular weight $\left(\mathrm{M}_{\mathrm{n}}\right)$ of $40.6 \mathrm{KDa}$ was used to formulate Dox-loaded NPs. Prior to drug encapsulation, Dox$\mathrm{HCl}$ was neutralized to generate Dox, following reported procedures [32]. NPs were prepared using a nanoprecipitation method. Briefly, an acetone/DMSO (1:1, v/v) solution of ECT2 $(10 \mathrm{mg} / \mathrm{ml}, 1 \mathrm{ml})$ was slowly added to a stirred $(900 \mathrm{rpm})$ aqueous phase $(5 \mathrm{ml} \mathrm{DI}$ water). The mixture was allowed to stabilize for $2 \mathrm{~h}$ under constant agitation at room temperature to obtain blank-NPs. Dox- or NR-loaded NPs were prepared using an acetone/ DMSO $(1: 1, \mathrm{v} / \mathrm{v})$ solution of ECT2 $(10 \mathrm{mg} / \mathrm{ml}, 1 \mathrm{ml})$ containing $2 \mathrm{mg} / \mathrm{ml}$ Dox or $0.1 \mathrm{mg} / \mathrm{ml}$ NR. Centrifugation (4,000 rpm for $10 \mathrm{~min})$ was applied to all NP suspensions to remove large polymer aggregates. The supernatant containing NPs was collected, and the free drug or dye and the solvent were removed by filtration using Amicon regenerated cellulose centrifugal filters (MWCO $=30 \mathrm{kDa}$, EMD Millipore). The collected NPs were thoroughly washed with DI water or phosphate buffered saline (PBS, pH 7.4) three times by centrifugation using the centrifugal filters. The resultant formulations were immediately subjected to physical and biological analyses.

\subsection{Characterization of NPs}

The hydrodynamic diameters of NPs were measured using a Zetasizer nanoZS (Malvern Instruments, Westborough, MA) by dynamic light scattering (DLS) at a concentration of 0.5 $\mathrm{mg} / \mathrm{ml}$ in PBS. Transmission electron microscopy (TEM) was used to examine the particle size and morphology. TEM samples were prepared by applying a drop of NP suspension (3 $\mu 1)$ directly onto a carbon-coated copper TEM grid. Samples were allowed to dry under ambient condition prior to imaging using a Tecnai G2 12 Twin TEM (FEI Company, Hillsboro, OR). The mean diameter of the NPs was estimated using ImageJ based on 50 counts of the particles from the TEM image.

\subsection{Drug/dye loading and release}

Aliquots (1 ml each) of the Dox-NPs and NR-NPs suspension in DI water were collected and lyophilized. The dried powder was weighed accurately before being dissolved in DMSO $(1 \mathrm{ml})$. The fluorescence intensity of the drug or dye was determined using a plate reader (DTX880 Multimode Detector, Beckman Coulter, Fullerton, CA) at $485 \mathrm{~nm}$ (excitation) / $595 \mathrm{~nm}$ (emission) for Dox and at $535 \mathrm{~nm}$ (excitation) / $595 \mathrm{~nm}$ (emission) for NR. The concentration of the drug or dye was then derived from a series of standards in DMSO at Dox concentrations of 3.125-25 $\mu \mathrm{g} / \mathrm{ml}$, and NR concentrations of $6.25-100 \mathrm{ng} / \mathrm{ml}$. The drugloading content $(\mathrm{LC})$ was defined as the amount of drug $(\mu \mathrm{g})$ loaded per milligram of DoxNPs. The drug encapsulation efficiency (EE, as percentage of the total) was calculated by dividing the amount of Dox loaded into the NPs with the amount of Dox initially added during the nanoprecipitation process. All measurements were carried out in triplicate, and the results were indicated as the mean $\pm \mathrm{SD}$.

The in vitro release of Dox and NR was analyzed under sink conditions. Briefly, freshly formulated NPs dispersed in serum containing cell culture medium were incubated at $37^{\circ} \mathrm{C}$. At predetermined time points, the release medium was separated from the NPs using centrifugal filters as described above. NPs were re-dispersed in fresh cell culture medium to continue the release study. The collected filtrates containing the released Dox or NR at each time point were lyophilized, and the resultant solid was re-dissolved in DMSO (undissolved 
salt was removed by centrifugation). Subsequently, the fluorescence intensity of the Dox and NR was measured using the plate reader, and the concentration was derived based on the standard curve as described above. Three repeats were performed for each time point, and the cumulative release profile was calculated by dividing the amount of drug or dye released in one specific measurement time by the total mass initially loaded.

\subsection{Hydrogel preparation}

Acrylated HA (HA-AC) and thiolated HA (HA-SH) were synthesized following previously reported procedures [33, 34]. Briefly, HA-AC was synthesized by reacting adipic acid dihydrazide-modified HA (HA-ADH, 35\% ADH incorporation determined by ${ }^{1} \mathrm{H}$ NMR [35]) with N-acryloxysuccinimide (NHS-AC) in DI water. The product was obtained as a lyophilized solid (yield: 70\%). Sulfhydryl groups were incorporated in HA via the reaction with a disulfide-containing dihydrazide compound, followed by reduction with dithiothreitol (DTT). The dry solid HA-SH was obtained after lyophilization (yield: $80 \%$ ). The HA derivatives were stored at $-20{ }^{\circ} \mathrm{C}$ prior to use. ${ }^{1} \mathrm{H}$ NMR analyses revealed a degree of modification of $9 \%$ and $45 \%$ for HA-AC and HA-SH, respectively [17]. The respective weight average molecular weights, as determined by GPC, were $345 \mathrm{kDa}$ and $314 \mathrm{kDa}$. HA hydrogels were prepared by mixing equal volume of HA-AC and HA-SH, dissolved in PBS at a concentration of $20 \mathrm{mg} / \mathrm{ml}$. The gelation process started $17 \mathrm{~min}$ after mixing and was completed after $6 \mathrm{~h}$ incubation at $37^{\circ} \mathrm{C}$ [17].

\subsection{Analysis of hydrogel pore size}

The pore size of the hydrogel was determined by a probe retention method [36] using a series of PEG-AuNPs with mean hydrodynamic diameters of 35, 50, 70 and $100 \mathrm{~nm}$, with the respective Au core of 5, 20, 40 and $70 \mathrm{~nm}$. The concentration of PEG-AuNPs in the stock solution, $\mathrm{C}_{0}(\mathrm{mg} / \mathrm{ml})$, was determined by UV-Vis spectrophotometer (Agilent Technologies, Santa Clara, CA) at a wavelength of 518, 524, 530 and $548 \mathrm{~nm}$ for 35, 50, 70 and $100 \mathrm{~nm}$ PEG-AuNPs, respectively. An aliquot $\left(\mathrm{V}_{0} \mathrm{ml}\right)$ of PEG-AuNPs stock solution was spun down by centrifugation and the pellet was re-dispersed in HA-AC solution in PBS ( $20 \mathrm{mg} / \mathrm{ml}, 75 \mu \mathrm{l})$. The HA-AC solution containing the disperse PEG-AuNPs was subsequently mixed with the HA-SH solution in PBS $(20 \mathrm{mg} / \mathrm{ml}, 75 \mu \mathrm{l})$. The mixture was incubated at $37^{\circ} \mathrm{C}$ for $6 \mathrm{~h}$. The hydrogels were then immersed in fresh PBS solution at room temperature for two days under constant shaking. The supernatant was collected and the hydrogel was washed with PBS. The concentration of released PEG-AuNPs $\left(\mathrm{C}_{1}, \mathrm{mg} / \mathrm{ml}\right)$ in the combined supernatant and the washing solution (total volume $V_{1}$ ) was determined by UV-Vis spectrophotometer. The retention of PEG-AuNPs in the hydrogel was quantified as follows: $\left(\left(\mathrm{C}_{0} \times \mathrm{V}_{0}-\mathrm{C}_{1} \times \mathrm{V}_{1}\right) / \mathrm{C}_{0} \times \mathrm{V}_{0}\right) \times 100$.

\subsection{Analysis of NP diffusion in HA hydrogels}

HA hydrogels were prepared as described above. The precursor mixture was added to the channel $\left(17 \times 3.8 \times 0.4 \mathrm{~mm}^{3}\right)$ connected by two cylindrical reservoirs at each end on a channel slide (ibidi, Verona, WI). After $6 \mathrm{~h}$ incubation at $37^{\circ} \mathrm{C}$, one of the reservoirs was filled with PBS containing NR-NPs $(1 \mathrm{mg} / \mathrm{ml}, 70 \mu \mathrm{l})$ and the other with PBS. The device was equilibrated at $37{ }^{\circ} \mathrm{C}$ for $18 \mathrm{~h}$. Control experiments using free NR $(1 \mu \mathrm{g} / \mathrm{ml}$ in PBS $)$ were performed as described above. Fluorescence images (16-bit) were taken with a PCO-Tech Pixelfly CCD camera after being magnified 5 times using a lab-built fluorescence microscope. A 1W $470 \mathrm{~nm}$ LED was used to excite the NR using an epifluorescence design, and the fluorescent light was filtered through a $570 \mathrm{~nm}$ long-pass filter. Image J was used to construct a $0.8 \mathrm{~mm} \times 2.5 \mathrm{~mm}$ image from a row scan of four images, and to generate intensity line profiles. The background intensity was subtracted from all line profiles prior to curve fitting (Igor Pro, Wavemetrics). The concentration profile for NR-NPs was fitted to 
the following one-dimensional model to obtain the diffusion coefficient in the HA hydrogel [37]:

$$
C(x, t) \propto \operatorname{erfc}\left(\frac{x}{2 \sqrt{D_{e f f^{t}}}}\right)
$$

Where erfc is the complementary error function, $\mathrm{x}$ is the diffusion distance $(\mu \mathrm{m}), \mathrm{t}$ is time $(\mathrm{s})$, and $\mathrm{C}(\mathrm{x}, \mathrm{t})$ is the measured concentration (intensity) as a function of time ( $\mathrm{t}$ ) at a known distance $(\mathrm{x})$. The measurement was carried out with three independent repeats.

\subsection{Cell culture}

LNCaP prostate cancer cells were maintained in Corning (Lowell, MA) tissue culture flasks $\left(75 \mathrm{~cm}^{2}\right)$ at $37^{\circ} \mathrm{C}$ in $5 \%(\mathrm{v} / \mathrm{v}) \mathrm{CO}_{2}$ in a RPMI-1640 medium supplemented with $5 \%(\mathrm{v} / \mathrm{v})$ fetal bovine serum (FBS), $100 \mathrm{U} / \mathrm{mL}$ penicillin $\mathrm{G}$ sodium and $100 \mu \mathrm{g} / \mathrm{mL}$ streptomycin sulfate in $0.085 \%(\mathrm{v} / \mathrm{v})$ saline $(\mathrm{P} / \mathrm{S})$. The medium was changed every other day, and cells were routinely passaged using $0.25 \%(\mathrm{w} / \mathrm{v})$ trypsin containing ethylenediaminetetraacetic acid (EDTA*4Na). Hydrogel culture of LNCaP prostate cancer cells were performed following previously reported procedures [17]. Briefly, cell culture inserts were pre-wet with PBS before being placed into a 24-well culture plate. HA-SH $(100 \mu \mathrm{l}, 20 \mathrm{mg} / \mathrm{ml})$ was added to the HA-AC solution $(100 \mu \mathrm{l}, 20 \mathrm{mg} / \mathrm{ml})$ containing dispersed LNCaP cells ( 0.2 million). After thorough mixing, the cell suspension was transferred into the cell culture insert and was incubated for $45 \mathrm{~min}$ at $37{ }^{\circ} \mathrm{C}$ before the medium was added around the insert. The resultant cell-gel construct had a cylindrical geometry of $1.8 \mathrm{~mm}$ in height and $12 \mathrm{~mm}$ in diameter. The cell culture medium was changed every day for each culture.

\subsection{Expression of multidrug resistance proteins}

LNCaP cells were cultured on 2D or in 3D as described above. At day 7, cells on 2D plastic surfaces were trypsinized and collected. Cells cultured in HA hydrogels were harvested by degrading the HA matrices using HAase $(5 \mathrm{KU} / \mathrm{ml})$ at $37^{\circ} \mathrm{C}$ for $4 \mathrm{~h}$. RNA extraction, reverse transcription and quantitative polymerase chain reaction (qPCR) analysis using ABI Prism 7300 Sequence Detection System (AB Applied Biosystems, Foster City, CA) were performed as described previously [36]. Primer sequences for specific genes were as follows [17, 38]: MRP1 (XM_003281512.2): forward (5'-GTC GGA ACA AGT CGT GCC TG-3'), reverse (5'-CAA AGC CTC CAC CTC CTC A-3'); LRP (XM_004615945.1): forward (5'TGG CTG AGG TGG AGG TGA AG-3'), reverse (5'-ATC GGT GAT GAG GGT TGA TTT C-3'); $\beta$-actin (NM_001101.3, the housekeeping gene): forward (5'-GGA CTT CGA GCA AGA GAT GG-3'), reverse (5'-AGC ACT GTG TTG GCG TAC AG-3'). The relative gene expression was calculated using the equation below [36]:

$$
\text { ratio }=\frac{\mathrm{E}_{\text {target }} \Delta \mathrm{Ct}_{\text {target }}(\text { control-sample })}{\mathrm{E}_{\text {ref }} \Delta \mathrm{Ct}_{\text {ref }}(\text { control-sample })}
$$

where $\mathrm{E}_{\text {target }}$ and $\mathrm{E}_{\text {ref }}$ are the real time PCR efficiencies of the target and the reference genes, respectively. $\Delta \mathrm{Ct}_{\text {target }}$ is the difference in the threshold cycle $(\mathrm{Ct})$ of the target genes between the control and the test samples. $\Delta \mathrm{Ct}_{\mathrm{ref}}$ is the difference in the $\mathrm{Ct}$ value of the control versus the test samples with reference to $\beta$-actin.

To analyze the expression MDR proteins at the protein level, tumoroids in 3D hydrogel cultures were collected by the enzymatic degradation using HAase as described above. Single cell suspension was obtained by treating the tumoroids with trypsin. Cells on the 
monolayer after 7 days of culture were treated with the same concentration of HAase as used in 3D, and then were collected by trypsinization. Single cell suspensions from both $2 \mathrm{D}$ and $3 \mathrm{D}$ cultures were plated onto the 8 -well chamber slides at the same density $\left(5 \times 10^{4}\right.$ cells per well). Immunocytochemistry staining for MRP1, LRP and cell nucleus were performed $24 \mathrm{~h}$ after seeding, following previously reported procedures [17]. Mouse anti-MRP1 mAb (1:4 in $3 \%$ BSA) and mouse anti-LRP mAb (1:20 in 3\% BSA) were used as the primary antibodies for the MRP1 and LRP, respectively. Goat anti-mouse IgG-FITC (1:400 in 3\% BSA) was used as the second antibody. Cell nucleus was stained with Draq5 (1:1000 in PBS). Samples were imaged using the Zeiss510 NLO confocal microscope.

\subsection{Cellular uptake of Dox and Dox-NPs}

LNCaP cells were grown on 8 well chamber slides as 2D monolayer or in HA hydrogels as 3D tumoroids, following the procedures described above. Cells on 2D and in 3D were incubated with free Dox $(50 \mu \mathrm{g} / \mathrm{ml}$ ) or Dox-NPs (containing $50 \mu \mathrm{g} / \mathrm{ml}$ equivalent Dox) for 2 $\mathrm{h}$ at $37{ }^{\circ} \mathrm{C}$. After extensive wash with PBS, cells or cell-gel constructs were inspected using Zeiss510 NLO confocal microscope to detect the internalized Dox or Dox-NPs (excitation wavelength at $488 \mathrm{~nm}$ with a band pass filter of 565-615 nm). Because of the short duration of the uptake study, tumoroids close to cell/gel constructs were imaged. Z-stack images were collected at a $3-\mu \mathrm{m}$ interval to observe the localization of Dox-NPs in the tumoroid.

\subsection{Endocytic mechanism}

LNCaP cells seeded in a 96 well plate at a density of $6.4 \times 10^{3}$ per well were incubated for $24 \mathrm{~h}$. After the medium was removed, cells were incubated at $37^{\circ} \mathrm{C}$ for $30 \mathrm{~min}$ with one of the following compounds dissolved in cell culture medium: $0.45 \mathrm{M}$ hypertonic sucrose and $10 \mu \mathrm{g} / \mathrm{ml}$ chlorpromazine hydrochloride (both are inhibitors of clathrin-mediated endocytosis); $5 \mathrm{mM} \mathrm{m}-\beta$-CD and $50 \mu \mathrm{g} / \mathrm{ml}$ genistein (both are inhibitors of caveolaemediated endocytosis); $8 \mu \mathrm{g} / \mathrm{ml}$ colchicine (an inhibitor of macropinocytosis) and $6 \mu \mathrm{g} / \mathrm{ml}$ quercetin (an inhibitor of caveolae- and clathrin-independent endocytosis), followed by a $2 \mathrm{~h}$ incubation with NR-NPs $(0.5 \mathrm{mg} / \mathrm{ml})$. Subsequently, 2D cultures were thoroughly washed with PBS, and the internalized NR was recovered by DMSO extraction and quantified using the plate reader. For 3D samples, LNCaP cells were cultured in HA-based hydrogel for 7 days before the treatment. After the inhibitor treatment, cell-gel constructs were exposed to NR-NPs for $24 \mathrm{~h}$ at $37^{\circ} \mathrm{C}$. Constructs were then degraded by using HAase and the collected cells were subjected to DMSO extraction. The mean fluorescence intensity of cells cultured on $2 \mathrm{D}$ and in $3 \mathrm{D}$ without any inhibitor treatment served as the control and was considered to be $100 \%$. The fluorescence intensity of cells treated with various inhibitors was compared with the control group to obtain the percentage of cellular uptake.

\subsection{Drug treatment and apoptosis assay}

Cells cultured on 2D in a 12-well plate and in 3D in HA hydrogels as stated above were allowed to proliferate for $24 \mathrm{~h}$ and 7 days respectively, to reach a similar cell number of 2.5 $\times 10^{5}$ [17]. Fresh medium containing free Dox or Dox-NPs at various concentrations were then added to the respective cultures and the drug treatment was allowed to proceed for $24 \mathrm{~h}$. Subsequently, cells were collected by trypsinization or HAase degradation for 2D and 3D respectively. Cell apoptosis analysis was performed using Cell Death Detection ELISA ${ }^{\text {PLUS }}$ according to manufacturer's instructions. Colorimetric detection by absorbance was carried out using the plate reader at $405 \mathrm{~nm}$.

\subsection{Statistical analysis}

All quantitative measurements were performed on three replicate samples. The results were reported as mean \pm standard deviation. Statistical significance was evaluated by analysis of 
variance (one-way ANOVA), followed by Tukey's post-hoc test. A P-value of $<0.05$ was considered to be statistically different.

\section{Results}

\subsection{Formulation and characterization of drug-loaded NPs}

The amphiphilic block copolymer, ECT2 ( $\mathrm{M}_{\mathrm{n}}: 40.6 \mathrm{~kg} / \mathrm{mol}$, PDI: 1.57$)$ containing $14 \mathrm{~mol} \%$ TSU in the hydrophobic block, was synthesized following a previously reported procedure [31], and used to formulate the NPs. Dox or a fluorescent hydrophobic dye, NR, was loaded into the NPs by a nanoprecipitation method without using of any surfactants. Particle size analysis by DLS (Figure 1A) showed that Dox-NPs and NR-NPs were similar in size (DoxNPs: $54 \pm 1 \mathrm{~nm}$; NR-NPs: $50 \pm 7 \mathrm{~nm}$ ) and exhibited an overlapping size distribution. Inspection of Dox-NPs by TEM revealed the presence of spherical objects with an estimated diameter of $40 \pm 5 \mathrm{~nm}$ (Figure 1B). The TEM results are in good agreement with DLS analyses, considering the fact that the TEM image was acquired on dry samples under vacuum whereas the DLS profile was obtained in an aqueous solution. The formulated NPs did not dissociate upon dilution, nor did they aggregate during prolonged incubation in both PBS and serum containing cell culture medium (Figure S1). Cytotoxicity evaluations on blank NPs confirmed that the NPs were not toxic to LNCaP cells under experimental conditions employed in the study (Figure S2).

Dox was effectively entrapped in the NPs with a loading content and encapsulation efficiency of $75.6 \pm 3.5 \mu \mathrm{g} / \mathrm{mg}$ and $39.3 \pm 0.9 \%$, respectively. Comparable values were obtained from our previous studies using this type of amphiphilic copolymer as the drug carrier [39]. In vitro release was evaluated by incubating Dox-NPs in serum-containing cell culture medium under sink conditions at $37^{\circ} \mathrm{C}$ for up to 7 days (Figure 1C). From day 0 to day 3, Dox was released at a cumulative rate of $15.9 \pm 0.3 \mathrm{wt} \%$ per day. Thereafter, Dox was released at a slower rate $(8.4 \pm 0.2 \mathrm{wt} \%$ per day) until day 7 when the experiments were terminated. By day 7, a total of $81.2 \pm 0.8 \mathrm{wt} \%$ of Dox initially loaded was released. Separately, the loading content and encapsulation efficiency for NR were quantified as $3.2 \pm$ $0.1 \mu \mathrm{g} / \mathrm{mg}$ and $32.3 \pm 0.4 \%$, respectively. Less than $0.4 \mathrm{wt} \%$ of NR was released at day 1 and $12.1 \pm 2.4 \mathrm{wt} \% \mathrm{NR}$ was detected in serum containing media by day 7 (Figure 1C). The limited release of NR is attributed to the hydrophobicity of the dye [40]. The high retention of the hydrophobic fluorescent probe by NPs demonstrates the feasibility to use NR to track the location of NPs without undesirable dye leaking concerns.

\subsection{NP diffusion in HA hydrogels}

In our study, the HA hydrogel was developed to mimic the tumor-associated ECM, which is the first barrier to the NP-based cancer therapeutics [37]. We speculate that the diffusion of the ECT2-derived NPs through the hydrogels would be strongly dependent on the average pore size of the hydrogels, not the NP-matrix interaction, considering the fact that the NPs are PEGylated. To analyze the hydrogel microstructure, PEG-modified gold nanoparticles (PEG-AuNPs) ranging from 35 to $100 \mathrm{~nm}$ were employed as probes. PEG-AuNPs were encapsulated in the HA hydrogels in situ and the relative retention of PEG-AuNPs reflects the average pore size of the hydrogel matrix. For $35 \mathrm{~nm}$ PEG-AuNPs, approximately $27 \pm$ $4 \%$ of initially loaded particles was retained by the hydrogel after two days of incubation (Figure 2A). As the size of PEG-AuNPs increased, the average retention capacity increased accordingly, reaching a plateau value of $77 \pm 2 \%$ for $70 \mathrm{~nm}$ PEG-AuNPs. Further increase in particle size didn't result in any significant increase in the average retention for $100 \mathrm{~nm}$ PEG-AuNPs $(79 \pm 7 \%)$. When the size of the PEG-AuNPs is smaller than the average pore size of the hydrogel, the probe can diffuse out of the hydrogel without significant restriction, consequently a relatively low overall retention was observed. When the average pore size of 
the hydrogel became comparable to the size of PEG-AuNPs, high retention was observed. Large PEG-AuNPs entrapped in the hydrogel could not diffuse out due to the steric hindrance imposed by the hydrogel matrix. Our probe retention experiments suggest that the HA hydrogel contains water-filled pores of approximately $70-100 \mathrm{~nm}$. The estimated pore size is in agreement with the results observed by cryogenic scanning electron microscopy (CryoSEM) as reported in our previous study [17].

We next evaluated the diffusive properties of the polymeric NPs in HA hydrogels (Figure 2B). NR was entrapped in NPs as the fluorescent probe. The NR-NPs suspension was placed in contact with one end of the hydrogel-filled channel. Infiltration of NR-NPs into the HA matrices was visualized using a fluorescence microscope after NPs were equilibrated with the HA hydrogel for $18 \mathrm{~h}$. NR-NPs were found to distribute across the hydrogel-filled channel in a gradient fashion, reaching the interior of the channel at least $1000 \mu \mathrm{m}$ away from the source reservoir in $18 \mathrm{~h}$ (Figure $2 \mathrm{~B}(\mathrm{a})$ ). By fitting the intensity profile of the NRNPs (Figure $2 B(b)$ ) to a one-dimensional diffusion model [37], the diffusion coefficient $\left(D_{1}\right)$ of NR-NPs was calculated as $4.04 \pm 0.03 \mu \mathrm{m}^{2} / \mathrm{s}$. As a control experiment, free NR solution $(1 \mu \mathrm{g} / \mathrm{ml})$ was prepared and the diffusion study was performed similarly as that for NR-NPs. As expected, no fluorescence signal was detected for the free NR within the hydrogel. This can be attributed to the fact that the fluorescence of the free dye was quenched in water [41]. Therefore, the fluorescent signal detected is from NR molecules entrapped in the NPs, not from free NR release in the medium. The diffusion coefficient of NR-NPs in water $\left(D_{0}\right)$ was calculated as $9.21 \mu \mathrm{m}^{2} / \mathrm{s}$ using the Stokes-Einstein equation: $D=\frac{k_{B} T}{6 \pi r}$, where $\mathrm{k}_{\mathrm{B}}$ is the Boltzmann's constant, the viscosity ( $\eta$ ) of water at $295.6 \mathrm{~K}$ is $9.4 \times 10^{-4} \mathrm{~Pa} \bullet$ [ [37], and the hydrodynamic radius (r) of NR-NPs is $25 \mathrm{~nm}$ as measured by DLS. The lower $\mathrm{D}_{1}$ value, in comparison to $\mathrm{D}_{0}$, indicates the ability of the HA matrix to hinder the NP diffusion [37, 42].

\subsection{Characterization of engineered tumoroids}

In our previous investigation [17], we characterized PCa tumoroids grown from LNCaP cells in HA hydrogels, in terms of cell morphology, cell-cell adhesion, and the expression of pro-angiogenic factors. Herein, the expression of two important multidrug resistance proteins, MRP1 and LRP were first evaluated at the mRNA level by qPCR analysis. Our results showed that the hydrogel culture resulted in a significant upregulation of MRP1 and LRP expression (Figure 3A). Specifically, cells in 3D expressed $3.2 \pm 1.2$ and $1.4 \pm 0.1$ times more MRP1 and LRP than those cultured on 2D at day 7 ( $<<0.05$, Figure $3 \mathrm{~A}$ ). To further corroborate our finding, cellular production of multidrug resistance proteins was assessed by immunocytochemical staining (Figure 3B and 3C). LNCaP cells with a history of 7-day 2D or 3D culture were trypsinized and re-plated on 2D for direct comparison purposes. Twenty four hours post plating, cells with a 2D culture history appeared larger and their cytoplasm was more elongated, whereas those with a 3D culture history appeared smaller and were prone to aggregate. The difference in cell morphology implies that cells with a history of 3D culture may still maintain their 3D phenotype after being re-plated on 2D plastic surface. For both MRP1 and LRP, only a faint background staining was detected for cells cultured on 2D. Contrarily, cells with a history of 3D hydrogel culture exhibited robust MRP1 and LRP staining (Figure 3B and 3C), indicating a significant overexpression of these two multidrug resistance proteins in cells grown under 3D conditions. Overall, the trend obtained from immunostaining is consistent with the qPCR results.

\subsection{Evaluation of Dox-NPs using the engineered tumor models}

Dox's intrinsic fluorescence enables the direct monitoring of the intracellular transport of the NPs via confocal microscope. Free Dox and Dox-NPs were found to localize in different intracellular compartments after being exposed to cells cultured on $2 \mathrm{D}$ for $2 \mathrm{~h}$. The short 
exposure time was chosen to avoid complications introduced by Dox released from NPs at a longer incubation time. While a stronger fluorescent signal was found in the cell nuclei in the case of free Dox (Figure 4A), Dox-NPs were excluded from the nuclei and distributed predominantly in the cytoplasm (Figure 4B). These results confirm that Dox-NPs can be readily internalized by $\mathrm{LNCaP}$ cells and that limited Dox release from NPs occurred within the time frame of the experiment, given the fact that Dox signal in the cell nuclei was undetectable (Figure 4B). Interestingly, under 3D culture conditions, free Dox localized predominantly in the cytoplasm of individual cells in the tumoroids (Figure $4 \mathrm{C}$ and Figure S3A), rather than in the cell nuclei as observed for free Dox in 2D cultures (Figure 4A). On the other hand, Dox-NPs were found to be distributed mainly in the cytoplasm of 3D tumoroids (Figure 4D and Figure S3B). The faint pinkish background staining surrounding the tumoroid in Figure 4D could be a result of the Dox-NPs being retained by the HA matrix. To ascertain that Dox-NPs were indeed internalized by cells in 3D and not simply adhered to the surface of the spheroids, Z-stack slides of the confocal image at a 3- $\mu \mathrm{m}$ interval were examined. Our results (Figure 5) confirm the homogeneous penetration of Dox-NPs through the entire tumoroid.

Our cellular uptake studies show that Dox-NPs can be readily internalized by LNCaP cells. Next, we investigated the endocytic pathways involved in the cellular uptake of NPs, employing specific endocytic inhibitors (Figure 6). NR-NPs were used in these studies in place of Dox-NPs to eliminate possible cytotoxic effects induced by the released Dox. Under the 2D conditions when treated with colchicine, a macropinocytosis inhibitor, cellular uptake of NR-NPs was reduced by $32 \pm 4 \%(\mathrm{p}<0.05)$ relative to the untreated controls. Treatment on 2D monolayer cultures with other inhibitors did not significantly alter the degree of NP uptake. As shown in Figure 6, the inhibitory effects of M- $\beta-C D$, genistein (both inhibit caveolae-mediated endocytosis) or colchicine on 3D cultures was evidenced by $34 \pm 1 \%, 27 \pm 2 \%$ and $23 \pm 2 \%$ ( $\mathrm{p}<0.05$ ) reduction of NP uptake, respectively. These results suggest that cells cultured on 2D internalize NPs predominantly via the macropinocytosis mechanism, whereas those in 3D employ both caveolae-mediated endocytosis and macropinocytosis mechanisms in NP uptake.

Following the cellular uptake studies, we evaluated the toxicity of free Dox and Dox-NPs on $2 \mathrm{D}$ and in 3D using a standard cell apoptosis assay. As shown in Figure 7, the drug induced a dose-dependent toxicity to the cultured cells, both on 2D and in 3D. The apoptosis experiments conducted on 2D cultures revealed that as the Dox concentration increased, both for free Dox and Dox-NPs, the respective apoptosis levels increased accordingly. A similar plateau level was reached (50.3 \pm 4.6 and $52.2 \pm 4.2$, fold change compared to untreated control) when the Dox concentration was higher than 10 and $20 \mu \mathrm{M}$ for free Dox and Dox-NPs, respectively. The half maximal inhibitory concentration $\left(\mathrm{IC}_{50}\right)$ for free Dox and Dox-NPs on 2D was calculated as $5.0 \pm 0.1 \mu \mathrm{M}$ and $11.0 \pm 0.8 \mu \mathrm{M}$, respectively. The apoptosis experiments conducted on 3D cultures showed a similar trend of dose dependence, although the plateau values of apoptosis were significantly lower as compared to the $2 \mathrm{D}$ cultures. Compared to cells cultured in 3D without any drug treatment, the apoptosis level for cells receiving the treatment of free Dox and Dox-NPs was $26.8 \pm 1.9$ and $25.0 \pm 1.2$ fold higher, respectively. The calculated $\mathrm{IC}_{50}$ value for free Dox and Dox-NPs in 3D cultures is $15.0 \pm 0.4$ and $12.3 \pm 0.8 \mu \mathrm{M}$, respectively.

\section{Discussion}

The hydrogel-derived tumor model reported herein simulates the native tumor tissue and its associated microenvironment. First, the HA hydrogel is viscoelastic and exhibits characteristic pore sizes similar to that found in the native tumor tissue, thereby serving as an artificial tumor-associated matrix. Second, cancer cells cultured in the hydrogel matrix 
organize into tumor-like structures and overexpress MDR proteins. Finally, the potential interactions between the aggregating cancer cells and the surrounding HA matrix, via the cell surface HA receptors such as CD44 and RHAMM, may recapitulate the early stage of tissue metastasis [26]. The engineered tumor model was used as a predictive platform for assessing therapeutic efficiencies of Dox-NPs.

It is well accepted that the transport of nano-therapeutics to the poorly perfused regions of tumor tissues is dominated by diffusion [43]. The rate of diffusion and the penetration depth depend on the size of the drug carrier and the interactions between the carrier and the interstitial matrices [43]. Although NPs in the range of 70-200 nm are optimal for tumor passive targeting through the EPR effect [4], NPs of $\sim 100 \mathrm{~nm}$ have been shown to diffuse poorly through the interstitial space in the tumor tissue [44]. As a result, NPs accumulate around tumor blood vessels and do not penetrate into the tumor parenchyma [44]. On the other hand, NPs smaller than $50 \mathrm{~nm}$ exhibited efficient transport capability in both the 3D multicellular tumor spheroids model [43] and tumor xenografts in vivo [45, 46]. In this study, NPs formulated from PEG- $b$-P(CL-ran-TSU) were used as the drug carrier. By controlling the molecular weight of our copolymer and fine-tuning the nanoprecipitation parameters [31, 47], NPs with an average diameter of $\sim 50 \mathrm{~nm}$ were obtained. Particles in this size range are expected to diffuse passively through the interstitial matrices in tumor tissues. The presence of PEG on the NP surface prevented the undesirable particle-matrix and particle-cell interactions [48].

The HA hydrogels, prepared from HA-AC and HA-SH, predominantly via a Michael type addition reaction, had an average elastic modulus of $234 \pm 30 \mathrm{~Pa}$ [17], comparable to that of the native lymph tissue through which PCa frequently metastasizes [17]. Although HA-SH can potentially react with biological entities to form S-S linkages, the free thiols on cell surfaces are of low abundance and the disulfide formation is much slower compared to the thiol-acrylate reaction [17]. Overall, our cell encapsulation protocol does not negatively impact the cellular functions $[49,50]$. Probe retention study using PEG-AuNPs revealed that the average pore size of the hydrogel was approximately $70-100 \mathrm{~nm}$, comparable to the spacing $(20-130 \mathrm{~nm})$ found in tumor ECMs [51]. As revealed from the diffusion study (Figure 2B), the HA-based matrix mimics the ECM barrier in the tumor tissues, and its presence reduced NP diffusivity by over 2 folds. Considering the similarity in pore size between the HA hydrogel and the interstitial matrices in tumor tissues, we suggest that the transport properties of NPs obtained from our HA hydrogel model could be translated to in vivo settings.

Drug resistance remains an obstacle to effective chemotherapy of solid tumors [52], and has been attributed to the overexpression of the MDR proteins by tumor cells [12,14]. The expression of two well-documented MDR proteins was investigated in this study. MRP1, a member of the superfamily of ATP-binding cassette (ABC) transporters, is well known for its function as a plasma membrane drug-efflux pump. MRP1 can extrude drugs from the cell and thereby decrease the intracellular drug accumulation, which ultimately cause the failure of chemotherapy [53, 54]. LRP, a major vault protein that is located in both cytoplasm and nuclear membrane, is also widely overexpressed in multidrug resistant tumor cells [55]. LRP may mediate MDR by the compartmentalization of drugs away from intracellular drug targets [55]. Specifically for Dox, it has been reported that LRP plays an important role in the transport of Dox from the cell nucleus (the active target of Dox) to the cytoplasm and thereby decreases the drug efficacy [56]. Our results show that the 3D hydrogel-based cell culture platform gives rise to cellular overexpression of MRP1 and LRP, possibly as a result of the competition for essential nutrients in cell aggregates [12]. The overexpression of MDR proteins has been suggested to be related to the native tumor microenvironment, as well as the tumor development process in vivo [13]. In agreement with our observations, 
Sanchez and colleagues found that the primary cultures of PCa cells derived from patients expressed significantly higher levels of MRP1 and LRP than PCa cell lines (i.e. LNCaP, PC3 and DU145 cell lines) cultured on 2D [13]. Our hydrogel-based 3D tumor model closely simulates the in vivo tumor growth condition, and the elevated expression of MDR proteins suggested a MDR cell phenotype. Therefore, the drug response from cells cultured in $3 \mathrm{D}$ should be more physiologically relevant than that from cells cultured on $2 \mathrm{D}$ monolayer.

Interestingly, Dox was found to localize in the nucleus of cells cultured on 2D (Figure 4A), but was restricted to the cytoplasm of cells cultured in 3D (Figure 4C). A possible explanation is that Dox in the nucleus was transported and sequestered to the cytoplasm by LRP [56, 57]. In agreement with this observation, a decreased nuclear to cytoplasmic drug ratio was also reported in MDR cells overexpressing LRP $[58,59]$. The cellular uptake study also revealed that Dox-NPs can penetrate the entire tumor spheroid and localize in the cytoplasm of individual cells (Figure 4D and Figure 5). The engineered tumoroids are likely to have loose structures, consisting of aggregating cells and interstitial matrix components. The HA immunostaining results (Figure S4) revealed the presence of HA in individual tumoroids. Such matrix-rich intercellular space within the spheroids may serve as a permissive pathway to facilitate the transport of NPs to the inner region of the tumoroids. These results are in line with previous reports confirming the NP penetration through the ECM between tumor cells to reach the inner region of the multicellular aggregates [ 43,45 , 60]. Particularly, Kim et al, have shown that polymeric micelles with an average diameter of $37 \mathrm{~nm}$ can penetrate into the core of $400 \mu \mathrm{m}$ human cervical tumor spheroids in $30 \mathrm{~min}$ [43]. In this study, the diffusion of NPs through the entire tumoroids is not surprising considering the relatively small size $(\sim 50 \mu \mathrm{m})$ of the multicellular aggregates of approximately $20-25$ cells per spheroid.

The HA-based tumor model is designed to mimic the in vivo tumor microenvironment to provide predictive results on the efficacy of NP-based cancer therapeutics. Our apoptosis assay revealed that the $\mathrm{IC}_{50}$ value for Dox-NPs was higher than that for the free drug tested under 2D culture conditions. This is expected because there is a time delay for Dox-NPs owing to the slow release of the drug from the polymeric NPs as compared to the immediate exposure of the free drug to the cultured cells [39]. The higher $\mathrm{IC}_{50}$ value and the lower plateau level of apoptotic cell death observed in 3D cultures treated with free Dox, as compared to that observed for $2 \mathrm{D}$ cultures, can be partially attributed to the aforementioned overexpressed MRP1 and LRP. Because Dox targets rapidly dividing cells and cells in 3D are less proliferative, the drug potency might be diminished in 3D cultures [17, 23]. This phenomenon cannot be explained by the limited drug access due to diffusion restrictions in the cell-gel construct, considering the fast diffusivity of the small molecule drug and the small size of the multicellular aggregates [14].

Given the time lag for Dox release from NPs, one would expect that the $\mathrm{IC}_{50}$ value for DoxNPs would be higher than that for the Dox under $3 \mathrm{D}$ culture conditions. Instead, similar $\mathrm{IC}_{50}$ values were observed. While low molecular weight hydrophobic drugs diffuse readily through the cell membrane, the polymeric NPs investigated here were internalized by LNCaP cells predominantly through caveolae-mediated endocytosis and macropinocytosis. In previously reported studies, researchers have shown that nano-therapeutics entered cells through these endocytic pathways can bypass the drug efflux pump and reverse the MDR [61, 62]. In our study, the apoptosis assay was performed after $24 \mathrm{~h}$ drug treatment. Our NP uptake experiments showed the Dox-NPs were rapidly taken up within $2 \mathrm{~h}$, during which minimal Dox was released from the NPs. Thus, cell death detected from 3D cultures was likely the result of intracellularly released Dox. Overall, NP formulation may avoid the drug efflux function of MRP1 and thereby the drug potency was enhanced. Of note, Because the 
HA matrix can hinder NP diffusion, and Dox released from NPs may potentially be pumped out by MRP1, it is reasonable to expect Dox-NPs to exhibit a higher efficacy in treating matrix-free tumoroids. Although the NP formulation may potentially bypass the drug efflux function of MRP1, the plateau level of apoptotic cell death in 3D Dox-NPs condition is significantly lower than that from the 2D Dox-NPs conditions. The discrepancy can be mainly attributed to the drug resistance effect of LRP and the slow growth of LNCaP cells in $3 \mathrm{D}$ as mentioned above.

\section{Conclusion}

In this investigation, we evaluated the efficacy of NP-based cancer therapeutics using an engineered PCa tumor model. The 3D platform recapitulates characteristics of native tumor tissue both physically and biologically. The HA-based matrix not only supports the tumoroids formation from LNCaP PCa cells but also serves as a diffusion barrier for NPs. Cell cultured under the biomimetic conditions expressed a higher level of MDR proteins than those cultured on 2D. Dox-loaded NPs with an average size of $54 \pm 1 \mathrm{~nm}$ can penetrate into the cell-gel construct, be taken-up by the resident cells and induce apoptotic responses. Moreover, cells cultured in 3D were more resistant to Dox treatment, in both soluble and NP-based forms, when compared to those grown under 2D conditions. The 3D tumor model provides an engineering advance that closely mimics the native carcinoma and can be used as an in vitro platform for the assessment of nanomedicine.

\section{Supplementary Material}

Refer to Web version on PubMed Central for supplementary material.

\section{Acknowledgments}

We thank Dr. Zhixiang Tong for his advice on immunostaining, Dr. Jeff Caplan for his expert assistance with confocal imaging and Ms Yingchao Chen for her assisting with the TEM imaging. We acknowledge Genzyme for the generous supply of HA. This work was supported in part by National Institutes of Health (NIH, R01DE022969 to MCFC and XJ, and P01CA098912 to MCFC), Delaware Health Science Alliance (DHSA to XJ), the University of Delaware (Graduate Fellowship to XX) and NASA (Cooperative Agreement, NNX12AR59G to CRS).

\section{References}

[1]. Peer D, Karp JM, Hong S, FaroKhzad OC, Margalit R, Langer R. Nanocarriers as an emerging platform for cancer therapy. Nat Nanotechnol. 2007; 2:751-60. [PubMed: 18654426]

[2]. Byrne JD, Betancourt T, Brannon-Peppas L. Active targeting schemes for nanoparticle systems in cancer therapeutics. Adv Drug Delivery Rev. 2008; 60:1615-26.

[3]. Moghimi SM, Hunter AC, Murray JC. Nanomedicine: current status and future prospects. FASEB J. 2005; 19:311-30. [PubMed: 15746175]

[4]. Kamaly N, Xiao Z, Valencia PM, Radovic-Moreno AF, Farokhzad OC. Targeted polymeric therapeutic nanoparticles: design, development and clinical translation. Chem Soc Rev. 2012; 41:2971-3010. [PubMed: 22388185]

[5]. Jain RK, Stylianopoulos T. Delivering nanomedicine to solid tumors. Nat Rev Clin Oncol. 2010; 7:653-64. [PubMed: 20838415]

[6]. Patel NR, Pattni BS, Abouzeid AH, Torchilin VP. Nanopreparations to overcome multidrug resistance in cancer. Adv Drug Deliv Rev. 2013; 65:1748-62. [PubMed: 23973912]

[7]. Wang X, Zhen X, Wang J, Zhang J, Wu W, Jiang X. Doxorubicin delivery to 3D multicellular spheroids and tumors based on boronic acid-rich chitosan nanoparticles. Biomaterials. 2013; 34:4667-79. [PubMed: 23537667]

[8]. Goodman TT, Ng CP, Pun SH. 3-D tissue culture systems for the evaluation and optimization of nanoparticle-based drug carriers. Bioconjugate Chem. 2008; 19:1951-9. 
[9]. Tong R, Hemmati HD, Langer R, Kohane DS. Photoswitchable nanoparticles for triggered tissue penetration and drug delivery. J Am Chem Soc. 2012; 134:8848-55. [PubMed: 22385538]

[10]. Sutherland RM. Cell and environment interactions in tumor microregions: the multicell spheroid model. Science. 1988; 240:177-84. [PubMed: 2451290]

[11]. Zhu H, Chen XP, Luo SF, Guan J, Zhang WG, Zhang BX. Involvement of hypoxia-inducible factor-1-alpha in multidrug resistance induced by hypoxia in HepG2 cells. J Exp Clin Canc Res. $2005 ; 24: 565-74$.

[12]. Zhu H, Luo S-f, Wang J, Li X, Wang H, Pu W-y, et al. Effect of environmental factors on chemoresistance of HepG2 cells by regulating hypoxia-inducible factor-1 alpha. Chin Med J. 2012; 125:1095-103. [PubMed: 22613537]

[13]. Sanchez C, Mendoza P, Contreras HR, Vergara J, McCubrey JA, Huidobro C, et al. Expression of multidrug resistance proteins in prostate cancer is related with cell sensitivity to chemotherapeutic drugs. Prostate. 2009; 69:1448-59. [PubMed: 19496068]

[14]. Wartenberg M, Frey C, Diedershagen H, Ritgen J, Hescheler J, Sauer H. Development of an intrinsic P-glycoprotein-mediated doxorubicin resistance in quiescent cell layers of large, multicellular prostate tumor spheroids. Int J Cancer. 1998; 75:855-63. [PubMed: 9506530]

[15]. Milane L, Duan Z, Amiji M. Role of hypoxia and glycolysis in the development of multi-drug resistance in human tumor cells and the establishment of an orthotopic multi-drug resistant tumor model in nude mice using hypoxic pre-conditioning. Canc Cell Int. 2011:11.

[16]. Wei LY, Roepe PD. Low external pH and osmotic shock increase the expression of human MDR protein. Biochemistry. 1994; 33:7229-38. [PubMed: 7911681]

[17]. Xu X, Gurski LA, Zhang C, Harrington DA, Farach-Carson MC, Jia XQ. Recreating the tumor microenvironment in a bilayer, hyaluronic acid hydrogel construct for the growth of prostate cancer spheroids. Biomaterials. 2012; 33:9049-60. [PubMed: 22999468]

[18]. Szot CS, Buchanan CF, Freeman JW, Rylander MN. 3 D in vitro bioengineered tumors based on collagen I hydrogels. Biomaterials. 2011; 32:7905-12. [PubMed: 21782234]

[19]. Chen L, Xiao ZF, Meng Y, Zhao YN, Han J, Su GN, et al. The enhancement of cancer stem cell properties of MCF-7 cells in 3D collagen scaffolds for modeling of cancer and anti-cancer drugs. Biomaterials. 2012; 33:1437-44. [PubMed: 22078807]

[20]. Cross VL, Zheng Y, Choi NW, Verbridge SS, Sutermaster BA, Bonassar LJ, et al. Dense type I collagen matrices that support cellular remodeling and microfabrication for studies of tumor angiogenesis and vasculogenesis in vitro. Biomaterials. 2010; 31:8596-607. [PubMed: 20727585]

[21]. Ingber DE. Can cancer be reversed by engineering the tumor microenvironment? Semin Cell Biol. 2008; 18:356-64.

[22]. Partanen JI, Nieminen AI, Makela TP, Klefstrom J. Suppression of oncogenic properties of cMyc by LKB1-controlled epithelial organization. Proc Natl Acad Sci U S A. 2007; 104:14694-9. [PubMed: 17766436]

[23]. Fong ELS, Lamhamedi-Cherradi S-E, Burdett E, Ramamoorthy V, Lazar AJ, Kasper FK, et al. Modeling ewing sarcoma tumors in vitro with 3D scaffolds. Proc Natl Acad Sci U S A. 2013; 110:6500-5. [PubMed: 23576741]

[24]. Fischbach C, Chen R, Matsumoto T, Schmelzle T, Brugge JS, Polverini PJ, et al. Engineering tumors with 3D scaffolds. Nat Methods. 2007; 4:855-60. [PubMed: 17767164]

[25]. Loessner D, Stok KS, Lutolf MP, Hutmacher DW, Clements JA, Rizzi SC. Bioengineered 3D platform to explore cell-ECM interactions and drug resistance of epithelial ovarian cancer cells. Biomaterials. 2010; 31:8494-506. [PubMed: 20709389]

[26]. Gurski LA, Xu X, Labrada LN, Nguyen NT, Xiao LX, van Golen KL, et al. Hyaluronan (HA) interacting proteins RHAMM and hyaluronidase impact prostate cancer cell behavior and invadopodia formation in 3D HA-based hydrogels. PLoS One. 2012:7.

[27]. Gurski LA, Jha AK, Zhang C, Jia XQ, Farach-Carson MC. Hyaluronic acid-based hydrogels as $3 \mathrm{D}$ matrices for in vitro evaluation of chemotherapeutic drugs using poorly adherent prostate cancer cells. Biomaterials. 2009; 30:6076-85. [PubMed: 19695694]

[28]. Lokeshwar VB, Cerwinka WH, Isoyama T, Lokeshwar BL. HYAL1 hyaluronidase in prostate cancer: a tumor promoter and suppressor. Cancer Res. 2005; 65:7782-9. [PubMed: 16140946] 
[29]. Lokeshwar VB, Rubinowicz D, Schroeder GL, Forgacs E, Minna JD, Block NL, et al. Stromal and epithelial expression of tumor markers hyaluronic acid and HYAL1 hyaluronidase in prostate cancer. J Biol Chem. 2001; 276:11922-32. [PubMed: 11278412]

[30]. Lees VC, Fan TPD, West DC. Angiogenesis in a delayed revascularization model is accelerated by angiogenic oligosaccharides of hyaluronan. Lab Invest. 1995; 73:259-66. [PubMed: 7543630]

[31]. Wang XY, Gurski LA, Zhong S, Xu XA, Pochan DJ, Farach-Carson MC, et al. Amphiphilic block co-polyesters bearing pendant cyclic ketal groups as nanocarriers for controlled release of camptothecin. J Biomater Sci, Polym Ed. 2011; 22:1275-98.

[32]. Altreuter DH, Dordick JS, Clark DS. Nonaqueous biocatalytic synthesis of new cytotoxic doxorubicin derivatives: exploiting unexpected differences in the regioselectivity of saltactivated and solubilized subtilisin. J Am Chem Soc. 2002; 124:1871-6. [PubMed: 11866597]

[33]. Lei YG, Gojgini S, Lam J, Segura T. The spreading, migration and proliferation of mouse mesenchymal stem cells cultured inside hyaluronic acid hydrogels. Biomaterials. 2011; 32:3947. [PubMed: 20933268]

[34]. Shu XZ, Liu YC, Luo Y, Roberts MC, Prestwich GD. Disulfide cross-linked hyaluronan hydrogels. Biomacromolecules. 2002; 3:1304-11. [PubMed: 12425669]

[35]. Jia XQ, Yeo Y, Clifton RJ, Jiao T, Kohane DS, Kobler JB, et al. Hyaluronic acid-based microgels and microgel networks for vocal fold regeneration. Biomacromolecules. 2006; 7:333644. [PubMed: 17154461]

[36]. Xu X, Jha AK, Duncan RL, Jia X. Heparin-decorated, hyaluronic acid-based hydrogel particles for the controlled release of bone morphogenetic protein 2. Acta Biomater. 2011; 7:3050-9. [PubMed: 21550426]

[37]. Wong C, Stylianopoulos T, Cui JA, Martin J, Chauhan VP, Jiang W, et al. Multistage nanoparticle delivery system for deep penetration into tumor tissue. Proc Natl Acad Sci U S A. 2011; 108:2426-31. [PubMed: 21245339]

[38]. Shi LX, Ma R, Lu R, Xu Q, Zhu ZF, Wang L, et al. Reversal effect of tyroservatide (YSV) tripeptide on multi-drug resistance in resistant human hepatocellular carcinoma cell line BEL-7402/5-FU. Cancer Lett. 2008; 269:101-10. [PubMed: 18538471]

[39]. Krishnan V, Xu X, Barwe SP, Yang X, Czymmek K, Waldman SA, et al. Dexamethasone-loaded block copolymer nanoparticles induce leukemia cell death and enhance therapeutic efficacy: a novel application in pediatric nanomedicine. Mol Pharm. 2013; 10:2199-210. [PubMed: 23194373]

[40]. Garcia-Garcia E, Andrieux K, Gil S, Kim HR, Le Doan T, Desmaele D, et al. A methodology to study intracellular distribution of nanoparticles in brain endothelial cells. Int J Pharm. 2005; 298:310-4. [PubMed: 15923094]

[41]. Greenspan P, Mayer EP, Fowler SD. Nile red: a selective fluorescent stain for intracellular lipid droplets. J Cell Biol. 1985; 100:965-73. [PubMed: 3972906]

[42]. Ramanujan S, Pluen A, McKee TD, Brown EB, Boucher Y, Jain RK. Diffusion and convection in collagen gels: implications for transport in the tumor interstitium. Biophys J. 2002; 83:165060. [PubMed: 12202388]

[43]. Kim TH, Mount CW, Gombotz WR, Pun SH. The delivery of doxorubicin to 3-D multicellular spheroids and tumors in a murine xenograft model using tumor-penetrating triblock polymeric micelles. Biomaterials. 2010; 31:7386-97. [PubMed: 20598741]

[44]. McKee TD, Grandi P, Mok W, Alexandrakis G, Insin N, Zimmer JP, et al. Degradation of fibrillar collagen in a human melanoma xenograft improves the efficacy of an oncolytic herpes simplex virus vector. Cancer Res. 2006; 66:2509-13. [PubMed: 16510565]

[45]. Huo SD, Ma HL, Huang KY, Liu J, Wei T, Jin SB, et al. Superior penetration and retention behavior of $50 \mathrm{~nm}$ gold nanoparticles in tumors. Cancer Res. 2013; 73:319-30. [PubMed: 23074284]

[46]. Huang KY, Ma HL, Liu J, Huo SD, Kumar A, Wei T, et al. Size-dependent localization and penetration of ultrasmall gold nanoparticles in cancer cells, multicellular spheroids, and tumors in vivo. ACS Nano. 2012; 6:4483-93. [PubMed: 22540892] 
[47]. Cheng J, Teply BA, Sherifi I, Sung J, Luther G, Gu FX, et al. Formulation of functionalized PLGA-PEG nanoparticles for in vivo targeted drug delivery. Biomaterials. 2007; 28:869-76. [PubMed: 17055572]

[48]. Han M, Oba M, Nishiyama N, Kano MR, Kizaka-Kondoh S, Kataoka K. Enhanced percolation and gene expression in tumor hypoxia by PEGylated polyplex micelles. Mol Ther. 2009; 17:1404-10. [PubMed: 19471245]

[49]. Shu XZ, Liu YC, Palumbo FS, Lu Y, Prestwich GD. In situ crosslinkable hyaluronan hydrogels for tissue engineering. Biomaterials. 2004; 25:1339-48. [PubMed: 14643608]

[50]. Ghosh K, Shu XZ, Mou R, Lombardi J, Prestwich GD, Rafailovich MH, et al. Rheological characterization of in situ cross-linkable hyaluronan hydrogels. Biomacromolecules. 2005; 6:2857-65. [PubMed: 16153128]

[51]. Pluen A, Boucher Y, Ramanujan S, McKee TD, Gohongi T, di Tomaso E, et al. Role of tumorhost interactions in interstitial diffusion of macromolecules: cranial vs. subcutaneous tumors. Proc Natl Acad Sci U S A. 2001; 98:4628-33. [PubMed: 11274375]

[52]. Gottesman MM, Fojo T, Bates SE. Multidrug resistance in cancer: role of ATP-dependent transporters. Nat Rev Cancer. 2002; 2:48-58. [PubMed: 11902585]

[53]. Zaman GJR, Flens MJ, Vanleusden MR, Dehaas M, Mulder HS, Lankelma J, et al. The human multidrug resistance-associated protein MRP is a plasma membrane drug-efflux pump. Proc Natl Acad Sci U S A. 1994; 91:8822-6. [PubMed: 7916458]

[54]. He SM, Li R, Kanwar JR, Zhou SF. Structural and functional properties of human multidrug resistance protein 1 (MRP1/ABCC1). Curr Med Chem. 2011; 18:439-81. [PubMed: 21143116]

[55]. Scheffer GL, Schroeijers AB, Izquierdo MA, Wiemer EAC, Scheper RJ. Lung resistance-related protein/major vault protein and vaults in multidrug-resistant cancer. Curr Opin Oncol. 2000; 12:550-6. [PubMed: 11085454]

[56]. Kitazono M, Sumizawa T, Takebayashi Y, Chen ZS, Furukawa T, Nagayama S, et al. Multidrug resistance and the lung resistance-related protein in human colon carcinoma SW-620 cells. J Natl Cancer Inst. 1999; 91:1647-53. [PubMed: 10511592]

[57]. Meschini S, Marra M, Calcabrini A, Monti E, Gariboldi M, Dolfini E, et al. Role of the lung resistance-related protein (LRP) in the drug sensitivity of cultured tumor cells. Toxicol in Vitro. 2002; 16:389-98. [PubMed: 12110277]

[58]. Schuurhuis GJ, Broxterman HJ, Delange JHM, Pinedo HM, Vanheijningen THM, Kuiper CM, et al. Early multidrug resistance, defined by changes in intracellular doxorubicin distribution, independent of P-glycoprotein. Br J Cancer. 1991; 64:857-61. [PubMed: 1681887]

[59]. Izquierdo MA, Shoemaker RH, Flens MJ, Scheffer GL, Wu L, Prather TR, et al. Overlapping phenotypes of multidrug resistance among panels of human cancer-cell lines. Int J Cancer. 1996; 65:230-7. [PubMed: 8567122]

[60]. Hamilton G. Multicellular spheroids as an in vitro tumor model. Cancer Lett. 1998; 131:29-34. [PubMed: 9839617]

[61]. Wang J, Sun J, Chen Q, Gao Y, Li L, Li H, et al. Star-shape copolymer of lysine-linked ditocopherol polyethylene glycol 2000 succinate for doxorubicin delivery with reversal of multidrug resistance. Biomaterials. 2012; 33:6877-88. [PubMed: 22770799]

[62]. Yan Y, Ochs CJ, Such GK, Heath JK, Nice EC, Caruso F. Bypassing multidrug resistance in cancer cells with biodegradable polymer capsules. Adv Mater (Weinheim, Ger). 2010; 22:5398403. 


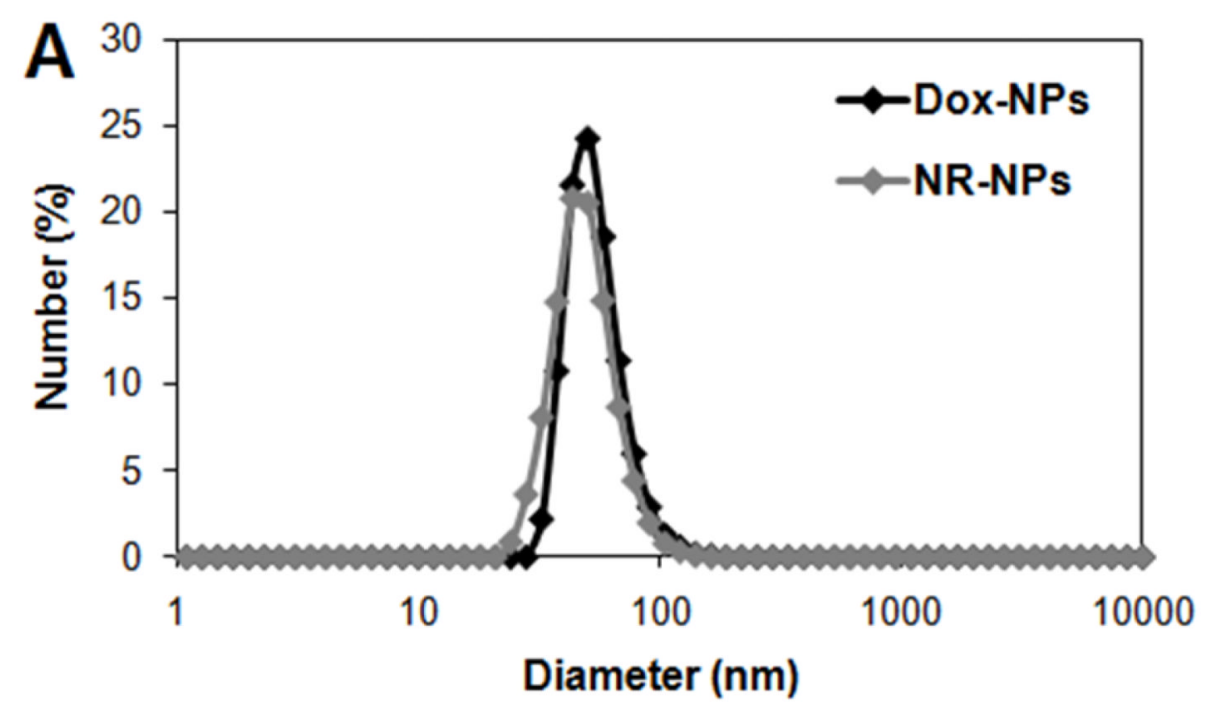

\section{B}




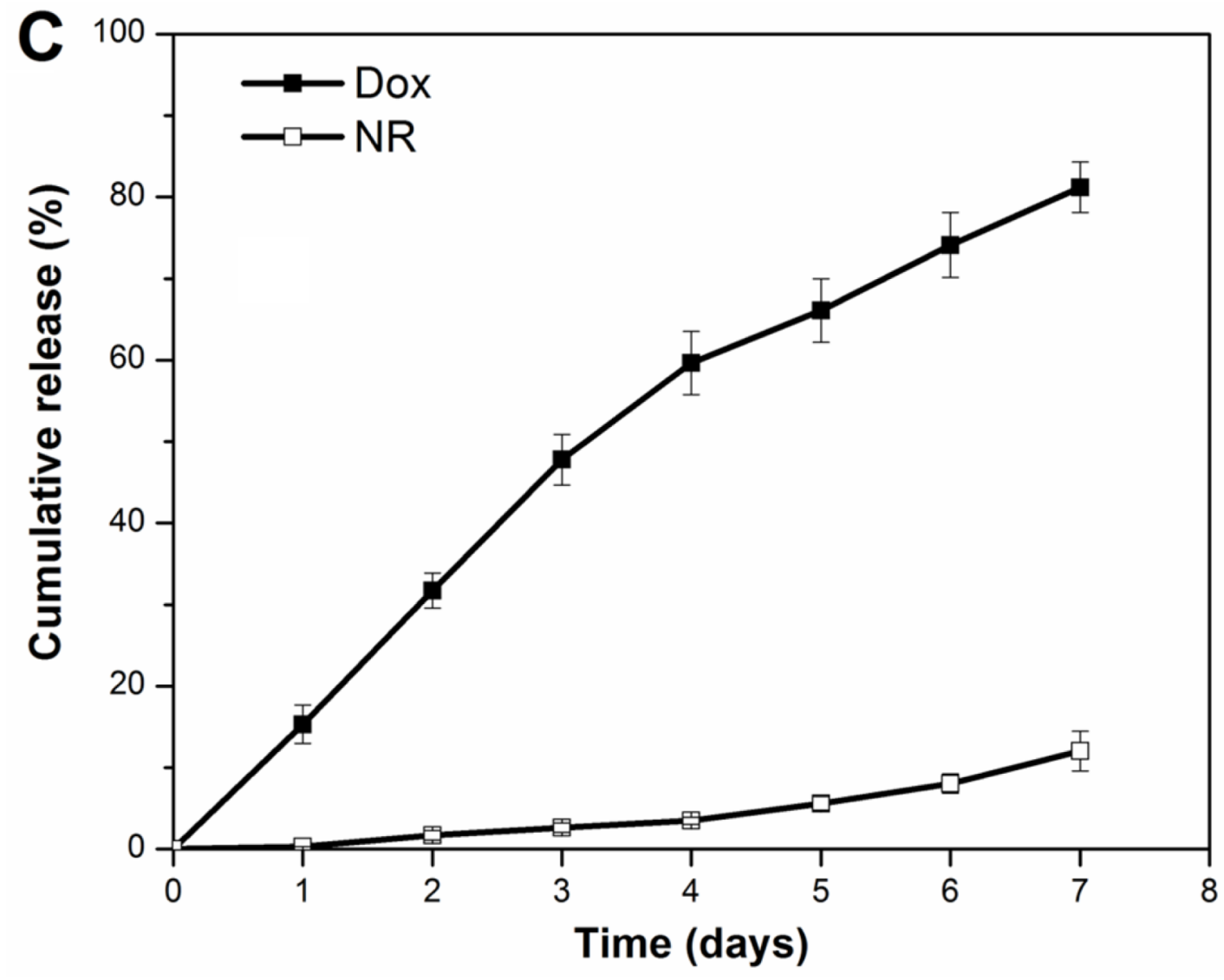

Fig. 1.

Characterization of Dox- and NR-loaded NPs. (A) DLS analysis (number-based size distribution) of Dox-NPs (black) and NR-NPs (gray). NPs were dispersed in PBS at a concentration of $0.5 \mathrm{mg} / \mathrm{ml}$ for DLS analysis. (B) Transmission electron micrograph of DoxNPs dried on carbon-coated copper grid. Image was acquired without any staining. (C) In vitro release of Dox (filled) and NR (open) from NPs in serum-containing cell culture medium at $37^{\circ} \mathrm{C}$. 


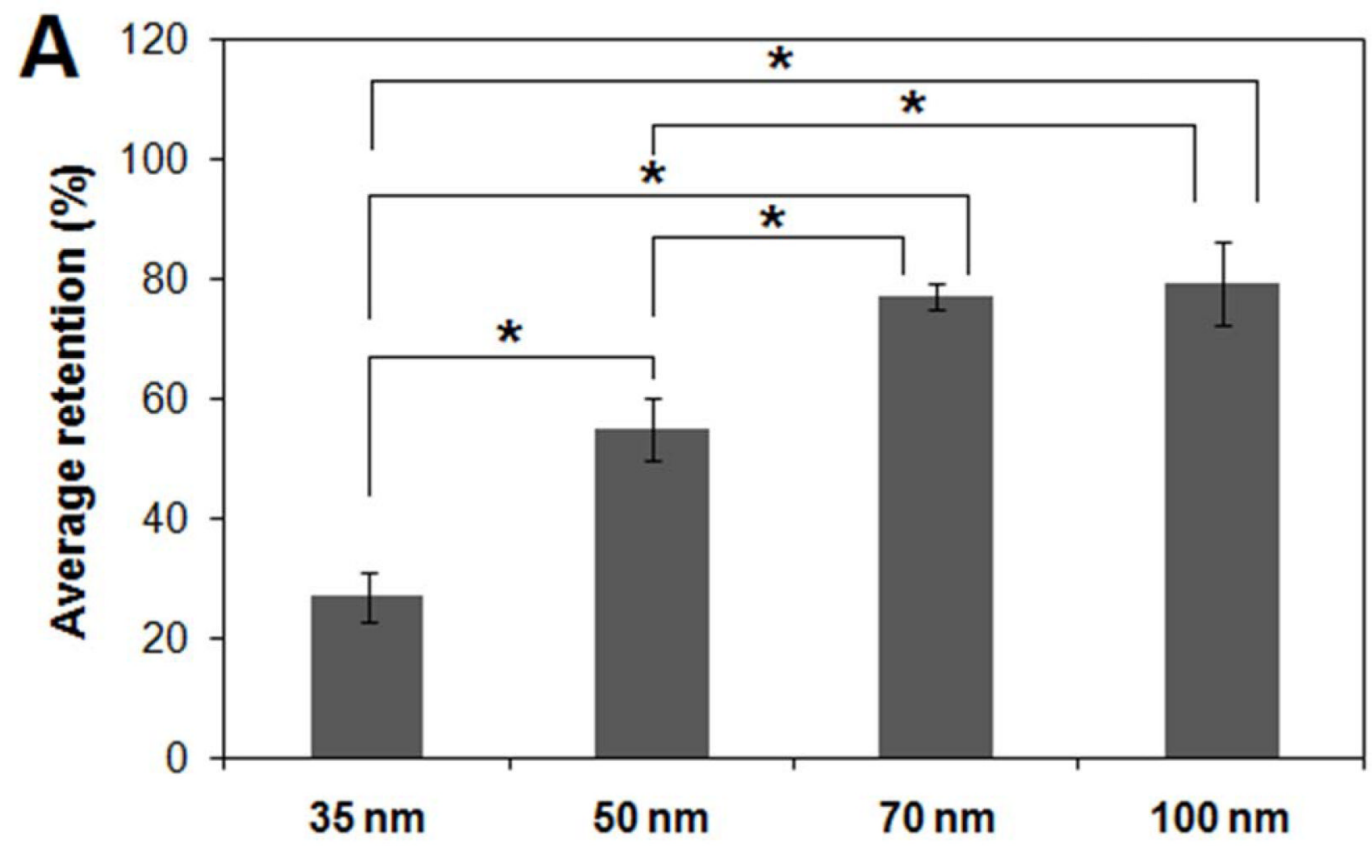




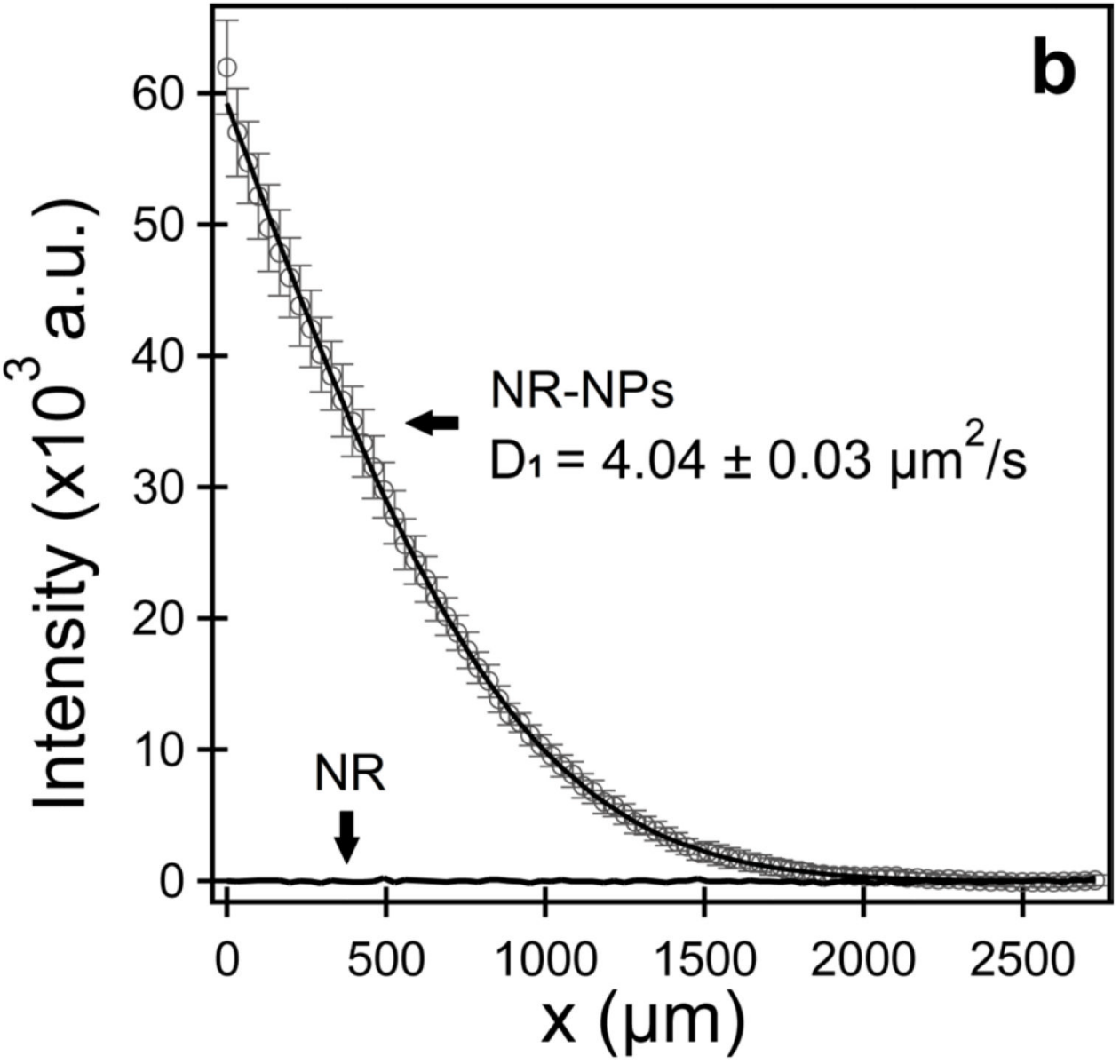

Fig. 2.

Analysis of hydrogel pore size and NP diffusion in the hydrogels. (A) Analysis of hydrogel pore size by probe retention. PEG-AuNPs with an average diameter of 35, 50, 70 and 100 $\mathrm{nm}$ were used as the probe (*: significant difference, $\mathrm{p}<0.05$ ). (B) Analysis of NP diffusion in HA hydrogels. Hydrogels were equilibrated with NR-NPs for $18 \mathrm{~h}$ prior to the analysis.

(a) Fluorescence image of HA hydrogel containing infiltrated NR-NPs. (b) Intensity profile of free NR and NR-NPs in HA hydrogel. The diffusion coefficient of NR-NPs in HA gels $\left(D_{1}\right)$ was calculated as $4.04 \pm 0.03 \mu \mathrm{m}^{2} / \mathrm{s}$ using a one-dimensional diffusion model. 

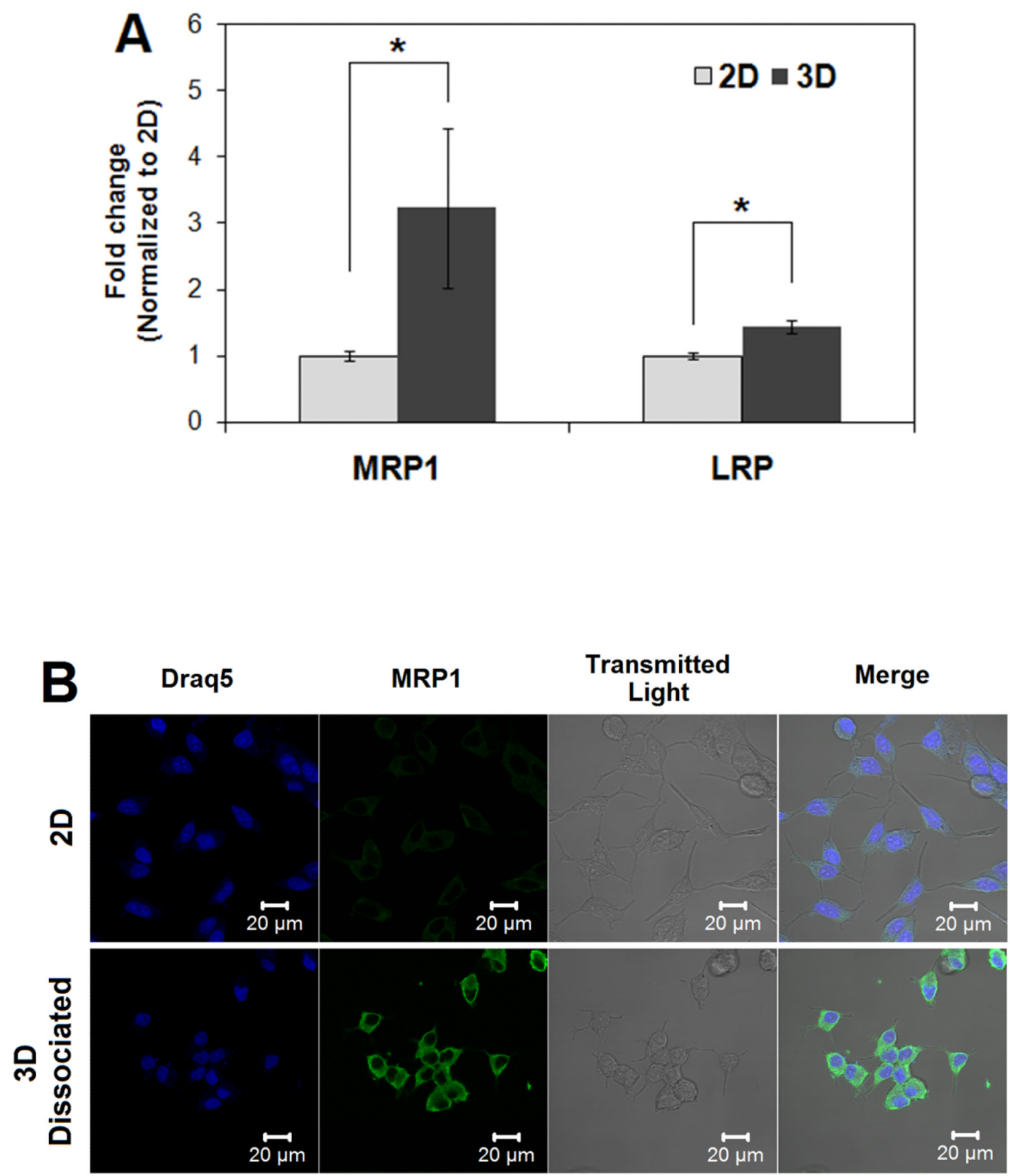

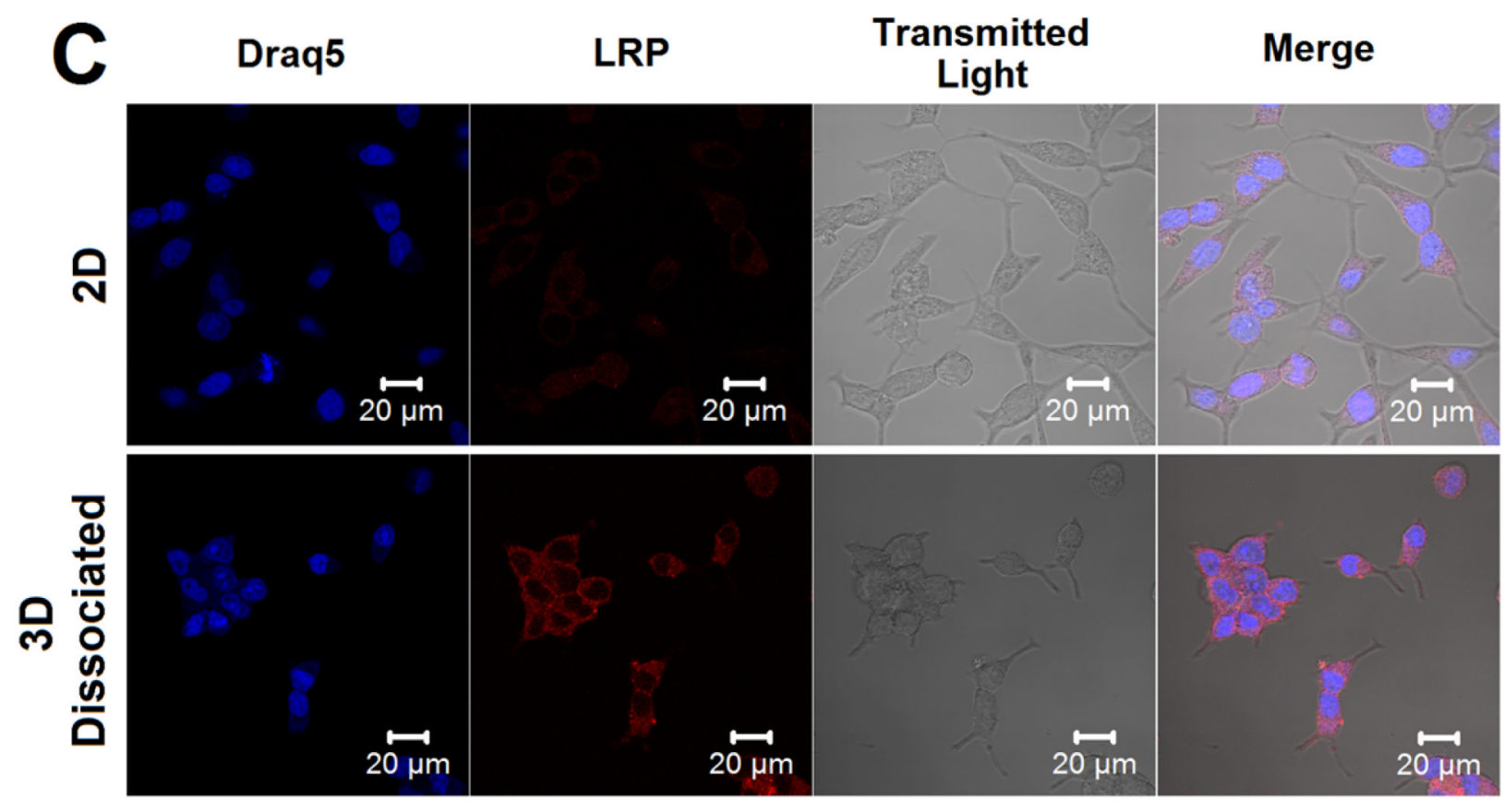

Fig. 3.

Characterization of MRP1 and LRP expression by LNCaP PCa cells cultured on 2D or in 3D HA gels. (A) Quantification of gene expression by qPCR. The expression was normalized to that of $2 \mathrm{D}$ at day 7 . $\beta$-actin served as the normalization control $(*$, significant difference, $\mathrm{p}<$ 0.05). (B and C) Confocal images of immunocytochemically stained LNCaP PCa cells with a history of 7-day culture on 2D monolayer or in 3D HA hydrogels. Cell nuclei, MRP1 (B) and LRP $(\mathrm{C})$ were stained blue, green and red respectively. 

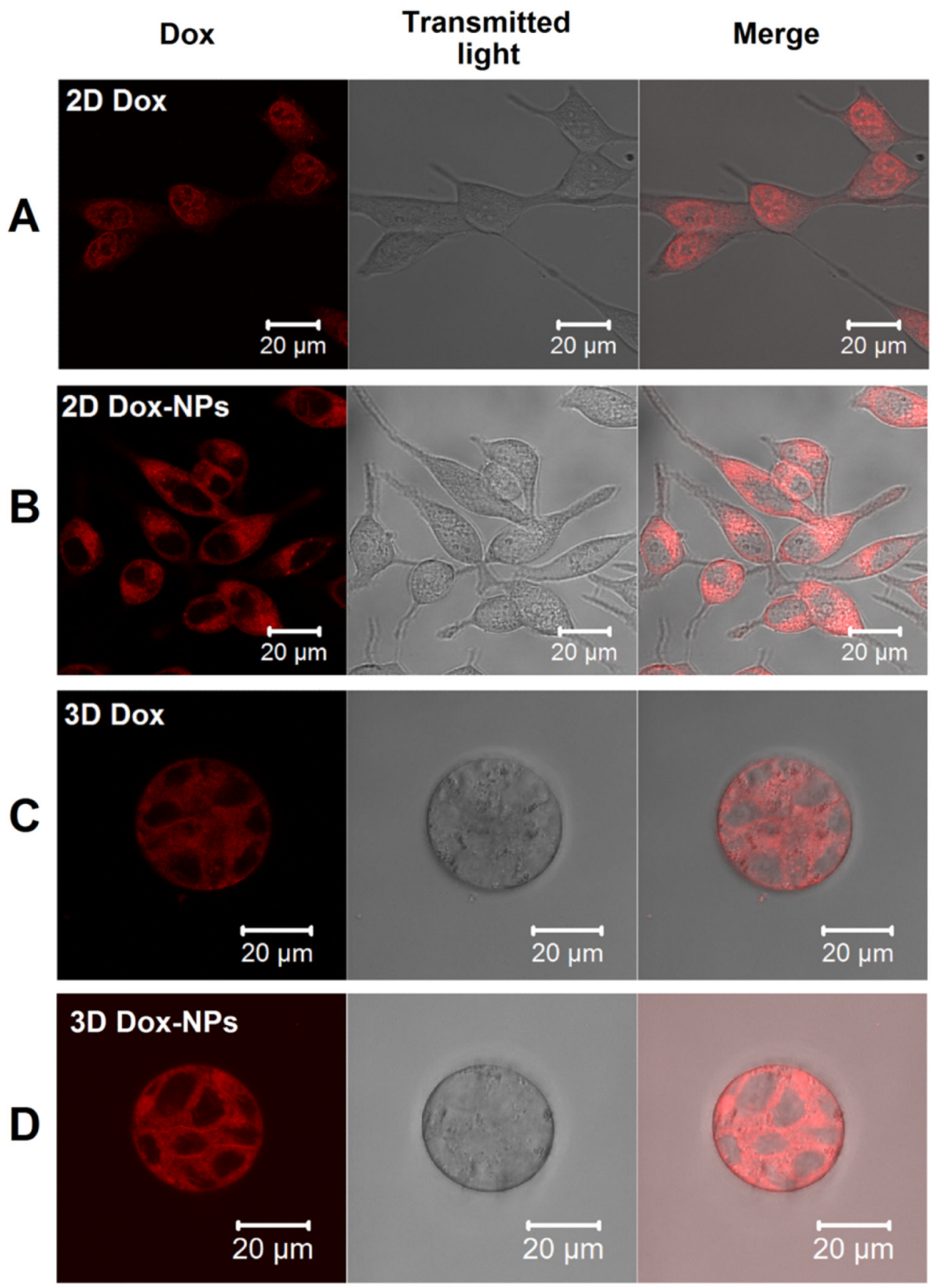

Fig. 4.

Confocal images of LNCaP PCa cells, cultured on 2D or in 3D, exposed to free Dox (50 $\mu \mathrm{g} /$ $\mathrm{ml}$ ) or Dox-NPs $(0.67 \mathrm{mg} / \mathrm{ml}$, corresponds to a Dox concentration of $50 \mu \mathrm{g} / \mathrm{ml})$ for $2 \mathrm{~h}$ at 37 ${ }^{\circ} \mathrm{C}$. On 2D, free Dox is primarily localized at the cell nucleus, while Dox-NPs are observed mainly in the cell cytoplasm. In 3D, both the free Dox and Dox-NPs are localized in the cytoplasm. 

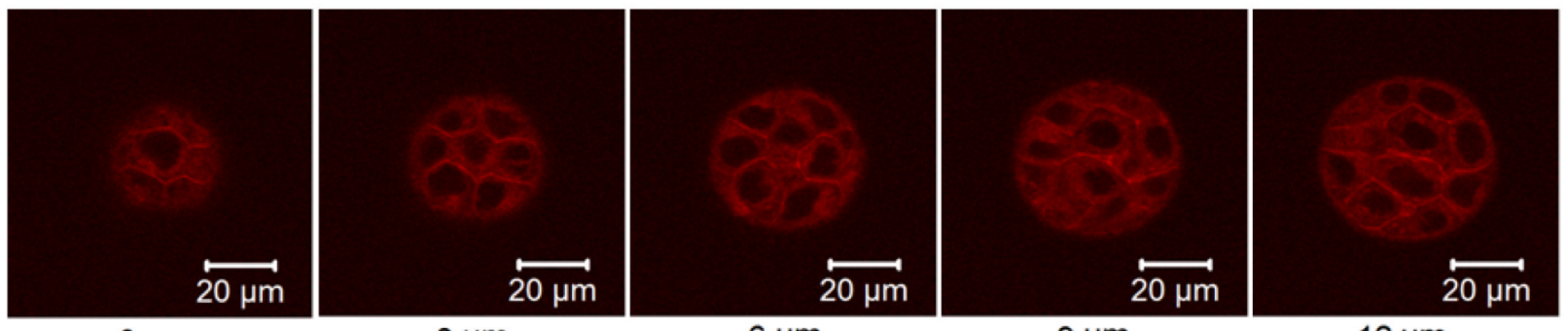

$0 \mu \mathrm{m}$

$3 \mu \mathrm{m}$

$6 \mu \mathrm{m}$

$9 \mu \mathrm{m}$

$12 \mu \mathrm{m}$
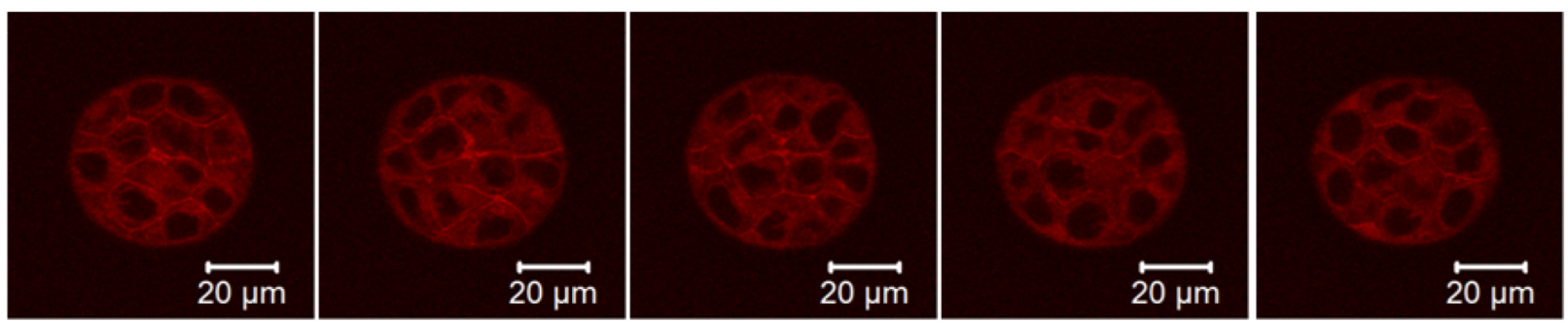

$15 \mu \mathrm{m}$

$18 \mu \mathrm{m}$

$21 \mu \mathrm{m}$

$24 \mu \mathrm{m}$

$27 \mu \mathrm{m}$

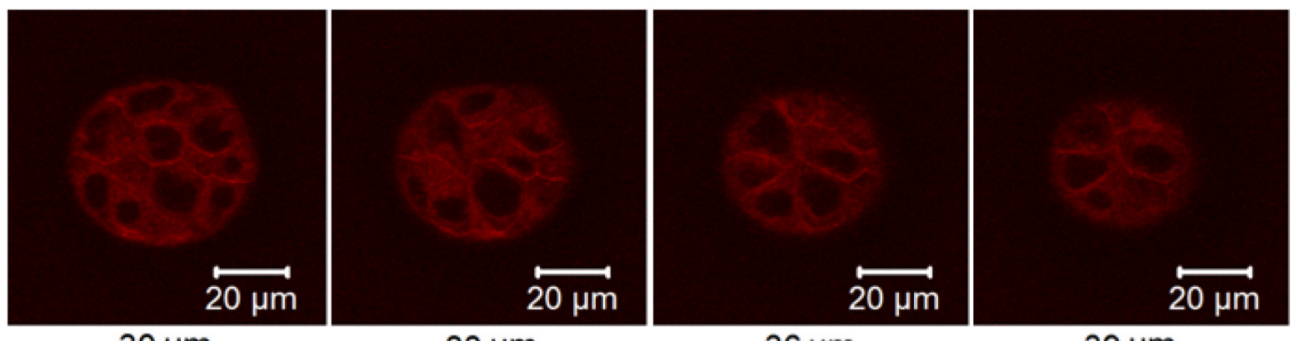

$30 \mu \mathrm{m}$

$33 \mu \mathrm{m}$

$36 \mu \mathrm{m}$

$39 \mu \mathrm{m}$

Fig. 5.

Confocal images (Z-stack, $3 \mu \mathrm{m}$ interval) of PCa tumoroids grown in the HA hydrogel and exposed to Dox-NPs $(0.67 \mathrm{mg} / \mathrm{ml})$ for $2 \mathrm{~h}$. Dox-NPs penetrated the entire tumoroid. 


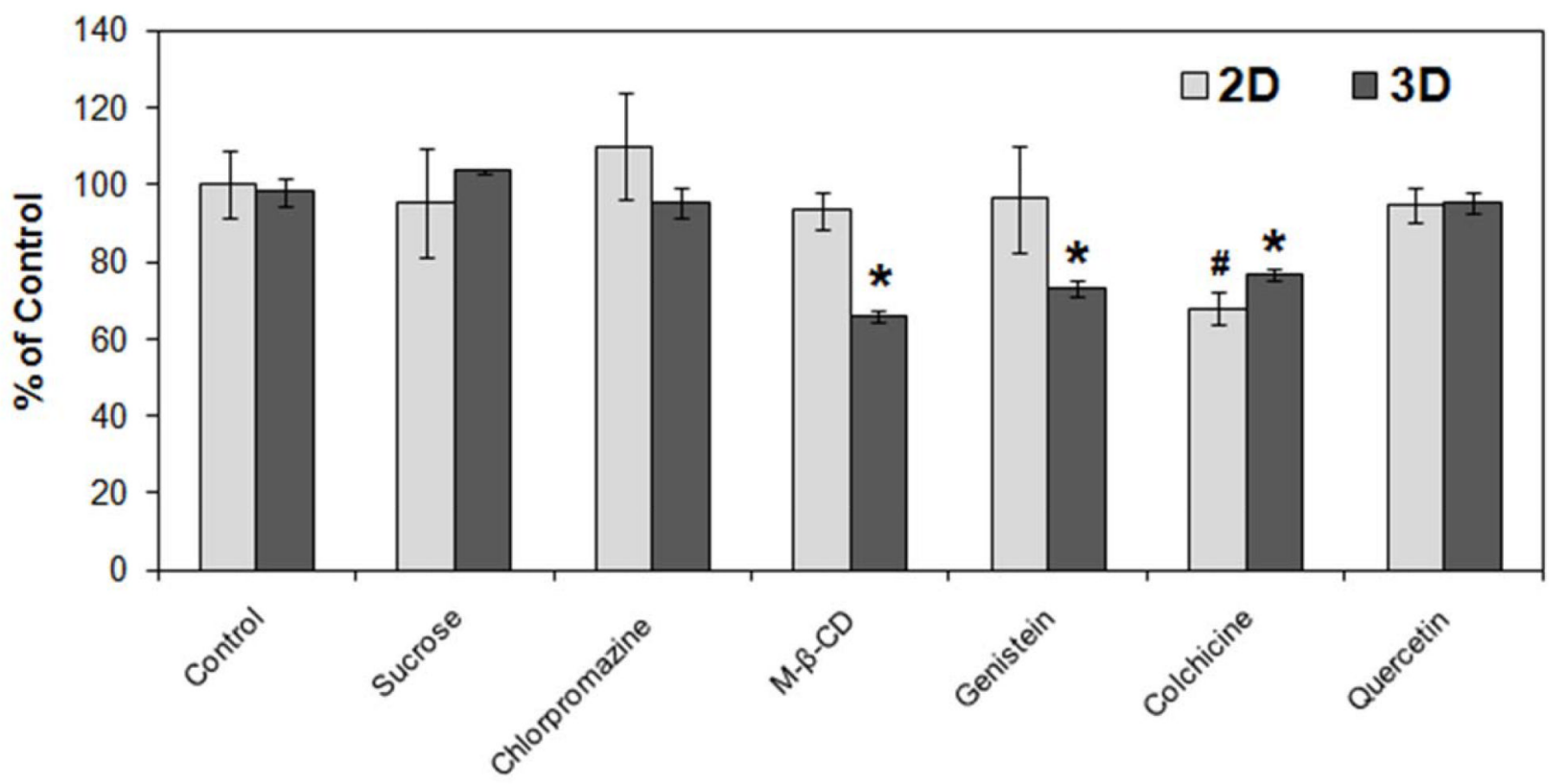

Fig. 6.

NP uptake by LNCaP prostate cancer cells cultured on $2 \mathrm{D}$ or in $3 \mathrm{D}$ in the presence of hypertonic sucrose $(0.45 \mathrm{M})$, chlorpromazine $(10 \mu \mathrm{g} / \mathrm{ml})$, methyl- $\beta$-cyclodextrin $(\mathrm{m}-\beta-\mathrm{CD}, 5$ $\mathrm{mM})$, genistein $(50 \mu \mathrm{g} / \mathrm{ml})$, colchicine $(8 \mu \mathrm{g} / \mathrm{ml})$ and quercetin $(6 \mu \mathrm{g} / \mathrm{ml})$. NR-NPs $(0.5 \mathrm{mg} /$ $\mathrm{ml}$ ) were used and the fluorescence intensity of NR in the non-inhibited cells was used as control. (\# and *, significant difference compared to 2D or 3D non-inhibited controls, respectively, $\mathrm{p}<0.05)$. 


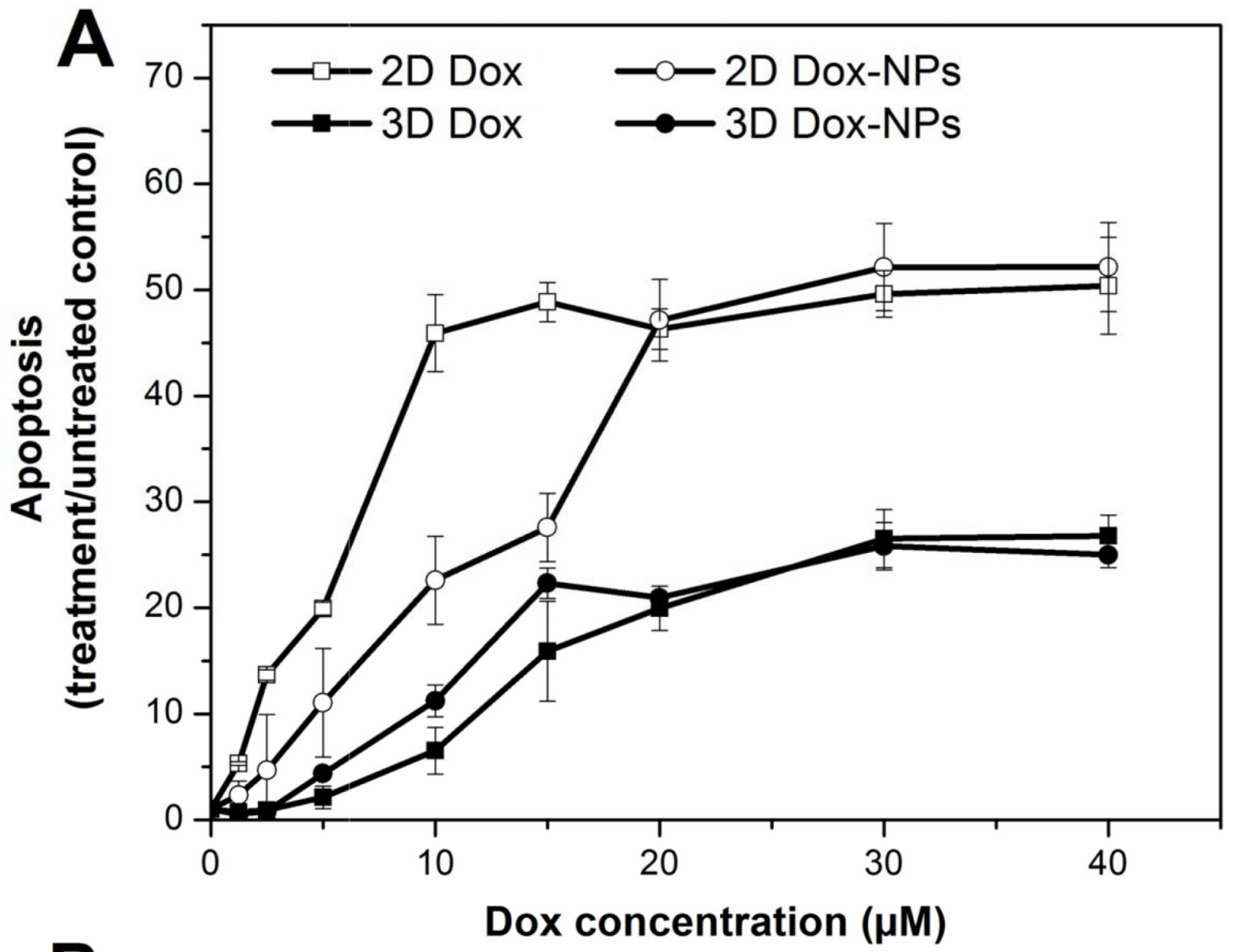

IC50 ( $\mu \mathrm{M})$
$5.0 \pm 0.1$

$11.0 \pm 0.8$

$15.0 \pm 0.4$

$12.3 \pm 0.8$

Fig. 7.

In vitro cytotoxicity of Dox and Dox-NPs in $2 \mathrm{D}$ and $3 \mathrm{D}$ cultures of LNCaP PCa cells. (A) Dose-dependent apoptosis induced by Dox and Dox-NPs. (B) Summary of the $\mathrm{IC}_{50}$ values $(\mu \mathrm{M})$ for Dox and Dox-NPs. (*, significant difference compared to the IC50 value of 2D Dox condition, $\mathrm{p}<0.05$ ) 